\title{
Deficiency of Microglial Autophagy Increases the Density of Oligodendrocytes and Susceptibility to Severe Forms of Seizures
}

\author{
Mahabub Maraj Alam, ${ }^{1}$ Xiao-Feng Zhao, ${ }^{1}$ Yuan Liao, ${ }^{2}$ Ramkumar Mathur, ${ }^{2}$ Sarah E. McCallum, ${ }^{1}$ \\ Joseph E. Mazurkiewicz, ${ }^{1}$ Matthew A. Adamo, ${ }^{3}$ Paul Feustel, ${ }^{1}$ Sophie Belin, ${ }^{1}$ (OYannick Poitelon, ${ }^{1}$ \\ Xinjun Cindy Zhu, ${ }^{2,4}$ and ${ }^{-}$Yunfei Huang ${ }^{1}$
}

https://doi.org/10.1523/ENEURO.0183-20.2021

${ }^{1}$ Department of Neuroscience and Experimental Therapeutics, Albany Medical College, Albany, NY 12208, ${ }^{2}$ Department of Molecular and Cellular Physiology, Albany Medical College, Albany, NY 12208, ${ }^{3}$ Department of Neurosurgery, Albany Medical College, Albany, NY 12208, and ${ }^{4}$ Department of Medicine, Albany Medical College, Albany, NY 12208

\begin{abstract}
Excessive activation of mTOR in microglia impairs CNS homeostasis and causes severe epilepsy. Autophagy constitutes an important part of mTOR signaling. The contribution of microglial autophagy to CNS homeostasis and epilepsy remains to be determined. Here, we report that ATG7KO mice deficient for autophagy in microglia display a marked increase of myelination markers, a higher density of mature oligodendrocytes (ODCs), and altered lengths of the nodes of Ranvier. Moreover, we found that deficiency of microglial autophagy (ATG7KO) leads to increased seizure susceptibility in three seizure models (pilocarpine, kainic acid, and amygdala kindling). We demonstrated that ATG7KO mice develop severe generalized seizures and display nearly $100 \%$ mortality to convulsions induced by pilocarpine and kainic acid. In the amygdala kindling model, we observed significant facilitation of contralateral propagation of seizures, a process underlying the development of generalized seizures. Taken together, our results reveal impaired microglial autophagy as a novel mechanism underlying altered homeostasis of ODCs and increased susceptibility to severe and fatal generalized seizures.
\end{abstract}

Key words: autophagy; epilepsy; microglia; mTOR; myelination; seizure

\section{Significance Statement}

Microglia play a critical role in CNS homeostasis, predominantly by impinging on neurons and astrocytes. A role for microglia in the development of oligodendrocytes (ODCs) has begun to be recognized, but the mechanism remains largely unknown. The present study uncovered a novel role of microglial autophagy in ODC homeostasis. Importantly, we found that deficiency of microglial autophagy causes severe forms of generalized seizures and high mortality, pointing to a strong association of altered ODC homeostasis and epilepsy. Our findings have implications in understanding severe forms of epilepsy.

\section{Introduction}

Macroautophagy/autophagy is a catabolic process that regulates cellular homeostasis via quality control of cellular proteins and organelles; it is also involved in the removal of invading pathogens and phagocytotic cellular

Received May 7, 2020; accepted January 2, 2021; First published January 20, 2021.

The authors declare no competing financial interests. debris (Levine and Klionsky, 2004; Rubinsztein et al., 2005). Autophagy is part of the mTOR signaling network. Autophagy activity is downregulated when mTOR is excessively activated under conditions such as the

Author contributions: M.M.A. and Y.H. designed research; M.M.A. performed research; M.M.A., X.-F.Z., Y.L., R.M., S.E.M., J.E.M., M.A.A., S.B., Y.P., and X.C.Z. contributed unpublished reagents/analytic tools; M.M.A. and P.F. analyzed data; M.M.A. and Y.H. wrote the paper. 
presence of growth factors, increased nutrient bioavailability, stress, and many others (Levine and Klionsky, 2004).

In the CNS, neuronal autophagy regulates homeostasis of axons and is implicated in neurodegeneration (Yamamoto and Yue, 2014). Autophagy activity is suppressed in human epilepsy conditions such as tuberous sclerosis complex (TSC), in which mTOR signaling is excessively activated (McMahon et al., 2012; Di Nardo et al., 2014; EbrahimiFakhari et al., 2016). Selective deficiency of autophagy activity in neurons leads to spontaneous seizures in mouse models, suggesting that neuronal autophagy constitutes part of the mTOR signaling network in the CNS and plays a critical role in maintaining neuronal excitability (McMahon et al., 2012).

The role of microglia and the microglial mTOR signaling network in epilepsy has recently garnered significant attention (Nonoda et al., 2009; Sierra et al., 2010; Abraham et al., 2012; Sosunov et al., 2012; Brewster et al., 2013; Eyo et al., 2014; Nguyen et al., 2015; Abiega et al., 2016; van Vliet et al., 2016; Wyatt-Johnson et al., 2017; Schartz et al., 2018; Zhao et al., 2018; Mo et al., 2019). Microglial mTOR activity is elevated in human epilepsy and animal models (Sosunov et al., 2012; Liu et al., 2014; Zhao et al., 2018). Excessive activation of mTOR in TSC1-deficient mice leads to hyperproliferation of microglia and astrocytes, increased phagocytotic activity, and severe spontaneous seizures (Zhao et al., 2018). In addition to their roles in regulating synaptic pruning and engulfing dead neurons and cellular debris (Nimmerjahn et al., 2005; Paolicelli et al., 2011; Schafer et al., 2012; Abiega et al., 2016; Wyatt-Johnson and Brewster, 2020), microglia also interact with other non-neuronal cells. For example, loss of TSC1 in microglia led to astrocyte proliferation (Zhao et al., 2018). In other recent studies, microglia have been reported to regulate oligodendrocyte (ODC) proliferation and myelination of neuronal axons (Miron, 2017; Wlodarczyk et al., 2017; Lloyd and Miron, 2019). However, the exact mechanism remains to be elucidated.

In the present study, we employed a microglial specific Cre line to delete a key autophagy gene, Atg7, from mouse microglia (Zhao et al., 2018, 2019) and characterized the impact of microglial autophagy deficiency on CNS homeostasis and seizure susceptibility.

\section{Material and Methods}

\section{Animals}

Animals were housed in the pathogen-free section of the Animal Research Facility. The animal facility is temperature and humidity controlled. The animals were kept in a

\footnotetext{
This work was supported by National Institutes of Health Grants NS093045 and NS112713 (to Y.H.) and NS110627 (to Y.P.).

Correspondence should be addressed to Yunfei Huang at huangy@amc.edu.

https://doi.org/10.1523/ENEURO.0183-20.2021

Copyright (C 2021 Alam et al.

This is an open-access article distributed under the terms of the Creative Commons Attribution 4.0 International license, which permits unrestricted use, distribution and reproduction in any medium provided that the original work is properly attributed.
}

12/12 $\mathrm{h}$ light/dark cycle period (lights on at 7 A.M.) and had ad libitum access to food and water. The experiments were performed according to the guidelines set by the Institutional Animal Care and Use Committee as well as the National Institutes of Health's Guide for the Care and Use of Laboratory Animals. Every effort was taken to reduce animal suffering and usage. Atg $7^{\mathrm{f} / \mathrm{f}}$ mice were donated by Masaaki Komatsu (McMahon et al., 2012). Cx3cr1-cre mice were acquired from the Mutant Mouse Resource and Research Center (Tg(Cx3cr1-Cre) MW126Gsat/Mmucd; stock \#036395-UCD). These Cx3cr1cre mice were shown to have a microglia specificity $>99 \%$ in a recent report (Zhao et al., 2019). ATG7 ${ }^{\text {Cx3cr1-creCKO }}$ (ATG7KO) were generated by crossing ATG7 floxed mice with Cx3cr1-cre mice. Cre-negative littermates were used as controls. Both male and female mice $8-10$ weeks old were used for the experiments.

\section{Brain tissue collection for Western blotting, RNA, and corpus callosum isolation}

Animals were injected with pentobarbital $(100 \mathrm{mg} / \mathrm{kg}$, i.p.) for anesthesia, and were transcardially perfused with $30 \mathrm{ml}$ of $1 \times$ PBS. Following perfusion, brains were removed from the skull and cortical and hippocampal tissues were dissected on ice-cold $1 \times$ PBS for RNA analysis. For Western blot analysis, forebrain tissue samples were collected and frozen in dry ice immediately for later use. For isolation of corpus callosum, whole-brain samples were harvested and dissected with the aid of a dissecting microscope to isolate corpus callosum. During the isolation process, brains were kept in ice-cold $1 \times$ PBS. Following isolation, corpus callosum tissue samples were immediately frozen in dry ice until later use.

\section{Western blot analysis}

We added $300 \mu$ of RIPA lysis buffer (150 mm sodium chloride, $1 \%$ NP-40, $0.5 \%$ sodium deoxycholate, $0.1 \%$ SDS, and $50 \mathrm{~mm}$ Tris-HCl; $\mathrm{pH} 8.0$ ) per $\sim 5 \mathrm{mg}$ of tissue sample. Tissue was then homogenized using an electronic homogenizer. Following homogenization, constant agitation was maintained for $30 \mathrm{~min}$ at $4^{\circ} \mathrm{C}$. Following agitation, samples were centrifuged for $20 \mathrm{~min}$ at $10,000 \times g$ at $4^{\circ} \mathrm{C}$. Supernatant containing protein was pipetted out and the pellet was discarded. Protein concentration was determined by using a Pierce BCA Protein Assay kit (according to the manufacturer's instructions) and a SmartSpec Plus Spectrophotometer. Following protein concentration measurement, an equal volume of $2 \times$ LDS (lysis buffer) was added to the tubes containing protein. Lysed samples were then incubated in a $95^{\circ} \mathrm{C}$ heat block for $5 \mathrm{~min} ; 12 \mu \mathrm{g}$ of protein sample were loaded into each well of a $12 \%$ BisTris gel and separated at a constant voltage of 80 V. Gels containing protein were transferred to nitrocellulose membranes in cold transfer buffer for $2 \mathrm{~h}$ at $4^{\circ} \mathrm{C}$. Constant current of $0.4 \mathrm{~A}$ was applied. Following transfer, membranes were cut according to desired sizes and blocked using 5\% non-fat milk in TBST (25 mм Tris- $\mathrm{HCl}, \mathrm{pH} 7.4,1.5 \mathrm{~m} \mathrm{NaCl}$, and $0.05 \%$ Tween 20 ) for $2 \mathrm{~h}$ at room temperature. 
Membranes were washed once with TBST following blocking. Primary antibodies were diluted in TBST and the membranes were incubated with primary antibody (Seen in Tables 1 and 2) overnight with mild shaking. The following morning, membranes were washed three to four times with TBST again with mild shaking, 15 min per wash. HRP-conjugated secondary antibody was diluted in $5 \%$ non-fat milk in TBST and the membranes were incubated for $2 \mathrm{~h}$ at room temperature. Following secondary antibody incubation, the membranes were washed three to four times as described above, and then developed using a Chemiluminescent Substrate kit (ThermoScientific, 34580). Sample size was six (three M, three F) for both control and mutant mice. Signal intensities were analyzed with ImageJ software.

\section{RNA isolation, RT-PCR, real-time PCR}

RNA was isolated from dissected cortical and hippocampal tissues, as well as from purified microglia. RNA was isolated by using TRIzol reagent according to the manufacturer's instructions. Tissue samples were homogenized in TRIzol before proceeding with the manufacturer's instructions. RNA pellets were re-suspended in $50 \mu \mathrm{l}$ of RNase-free water and incubated at $55^{\circ} \mathrm{C}$ for 5 min. RNA concentrations were measured by using a SmartSpec Plus Spectrophotometer. cDNA was synthesized by using a Verso cDNA Synthesis kit and the manufacturer's instructions were followed. $600 \mathrm{ng}$ of RNA was used for the synthesis of cDNA in a total volume of $50 \mu \mathrm{l}$. One to two microliters of cDNA templates were used for real-time PCR by using a SYBR Green qPCR master Mix kit in a Step One Plus Real-time PCR system. Each sample was evaluated in triplicate and the CT values were averaged before being subjected to normalization to GAPDH. All primer sequences used for GPCR are provided in Table 3. For cortical and hippocampal tissues as well as for purified microglia, sample sizes of $n=6$ (three $\mathrm{M}$, three $\mathrm{F}$ ) were used, and data are presented as an average.

\section{Purification of microglia from adult mouse brain}

Animals were sedated with pentobarbital $(100 \mathrm{mg} / \mathrm{kg}$, i.p.) and transcardially perfused with $30 \mathrm{ml}$ of $1 \times$ PBS. Mouse brains were dissected and dissociated in $1 \mathrm{ml}$ ice-cold serum-free medium (DMEM/F12 +1\% pen/ strep $+4.5 \mathrm{mg} / \mathrm{ml}$ glucose) and 3-ml dissociation medium (DMEM/F12 $+1 \mathrm{mg} / \mathrm{ml}$ papain +1.2 unit $/ \mathrm{ml}$ dispase II +20 units $/ \mathrm{ml}$ DNase I) per brain. Dissociated brain tissue solution was incubated at $37^{\circ} \mathrm{C}$ for $15 \mathrm{~min}$, and the solution was neutralized immediately with $3 \mathrm{ml}$ of neutralizing medium (DMEM/F12 + 10\% FBS $+4.5 \mathrm{mg} / \mathrm{ml}$ glucose). The suspension was further dissociated by aspirating up-and-down with a $1 \mathrm{ml}$ volume pipette and filtered through a $30-\mu \mathrm{m}$ filter. Myelin was removed by adding $8 \mathrm{ml}$ of $70 \%$ Percoll into the dissociated brain tissue solution. The tube containing the tissue solution was subjected to centrifugation for $10 \mathrm{~min}$ at $800 \times g$ at room temperature in a brake-free condition. At this point, cells were pelleted and resuspended in $500 \mu \mathrm{l}$ of FACS buffer (1\% BSA, $0.1 \%$ sodium azide, and $2 \mathrm{~mm}$ EDTA in $1 \times$ PBS; $\mathrm{pH} 7.5)$. Cells were centrifuged at $500 \times g$ for $5 \mathrm{~min}$ at $4^{\circ} \mathrm{C}$ and the pelleted cells were resuspended in $50 \mu \mathrm{l}$ of FACS buffer; $1 \mu \mathrm{l}$ of CD16/32 antibody was added to the cells to block Fc receptors and the suspension was incubated on ice for $10 \mathrm{~min}$. The cells were then incubated with primary CX3CR1-PE conjugated antibody for $15 \mathrm{~min}$ at $4^{\circ} \mathrm{C}$ according to the manufacturer's instructions. The cells were then washed with $500 \mu \mathrm{l}$ of FACS buffer and centrifuged at $500 \times g$ for $5 \mathrm{~min}$ at $4^{\circ} \mathrm{C}$. The pelleted cells were resuspended in $80 \mu \mathrm{l}$ of FACS buffer, and $20 \mu$ of anti-PE microbeads were added. The cells were incubated for $20 \mathrm{~min}$ in the dark at $4^{\circ} \mathrm{C}$, followed by washing in $500 \mu \mathrm{l}$ of FACS buffer and centrifuged for $5 \mathrm{~min}$ at $500 \times g$ at $4^{\circ} \mathrm{C}$. Washed cells were resuspended in $500 \mu \mathrm{l}$ of FACS buffer and passed through a magnetic Miltenyi MS column. The column was washed three times with $500 \mu \mathrm{l}$ of FACS buffer and then removed from the magnetic field. At this point, microglial cells remain in the MS column and need to be forced out with a plunger. Cells were eluted out of the MS column according to the manufacturer's instructions. Eluted cells were pelleted by centrifugation at $800 \times g$ for $10 \mathrm{~min}$ at $4^{\circ} \mathrm{C}$. FACS buffer was then removed and replaced with TRIzol for RNA extraction.

\section{Brain tissue collection for immunohistochemistry}

Animals were injected with pentobarbital $(100 \mathrm{mg} / \mathrm{kg}$, i.p.) for anesthesia, and were transcardially perfused with $30 \mathrm{ml}$ of $1 \times$ PBS followed by $30 \mathrm{ml}$ of $4 \%$ paraformaldehyde in $1 \times$ PBS (PFA). Brains were postfixed further for at least $48 \mathrm{~h}$ in PFA and were cyroprotected in $30 \%$ sucrose for an additional $48 \mathrm{~h}$ before sectioning. Cryoprotected brains were then embedded in Neg-50 (Thermoscientific, $6502)$ frozen sectioning medium, and $35-\mu \mathrm{m}$ coronal sections were cut using a Leica cryostat. Sectioned brain tissues were washed with $1 \times$ PBS and blocked with specific blocking buffer for immunohistochemistry analysis.

\section{Immunohistochemistry, acquisition of images, and image analysis}

The following protocol was used for immunostaining tissue sections with anti-lba1 (Wako, 019-19 471), anti-CD68 (Bio-Rad, MCA1957), anti-GFAP (Millipore, AB5541), antiNeuN (Cell Signaling, D4640) antibodies. Comparable sections of ATG7KO and littermate control mice were chosen for staining. Selected sections were put on a slide and dried for $5 \mathrm{~min}$. The sections were then washed with $1 \times$ PBS three times, $5 \mathrm{~min}$ each. The sections were then blocked and permeabilized with blocking buffer $(0.3 \%$ Triton X-100 and $10 \%$ BSA in $1 \times$ PBS) for at least $1 \mathrm{~h}$ at room temperature. Then antibodies were diluted in blocking buffer and the sections were incubated with diluted antibodies overnight at $4^{\circ} \mathrm{C}$. The following morning, the sections were washed with $1 \times$ PBS three times, $5 \mathrm{~min}$ per wash. Fluorophore-conjugated secondary antibodies were diluted in blocking buffer. The sections were incubated with secondary antibody for $2 \mathrm{~h}$ at room temperature and then washed with $1 \times$ PBS twice, $5 \mathrm{~min}$ per wash, then counterstained with DAPI (Sigma-Aldrich, D9542-1MG) diluted in 1× PBS for 5 min at room temperature, and then washed three times, $5 \mathrm{~min}$ per 
wash. Fluoromount G (SouthernBiotech, 0100-01) was overlaid on top of the brain sections and the slides were sealed with nail-polish. A confocal microscope (Zeiss LSM 880) was used to acquire images. A $25 \times$ water lens was used to collect images. To collect full-scale images, bounding grids were created. The grid was chosen to have the cortical layer directly above the hippocampus as well as the entire hippocampus. The z-layer was also added for image acquisition and a $15-\mu \mathrm{m}$-thick $z$-layer was chosen to image. The $z$-layer was chosen to have the maximum intensity. Images were taken in intervals of 1- $\mu \mathrm{m}$ thickness. Following acquisition, czi files were processed for airyscan processing, stitching of tiles, and to have maximum intensity projection. This was done by using ZEN Black 2.3. TIF format images were downloaded using ZEN Blue 2.3. For cell counting, Image J software was used and the "analyze particles" option was used to count cells. Data are presented to show cells per $10^{5} \mu \mathrm{m}^{2}$. The sample size is six (three Males, three Females) for both ATG7KO mice and littermate controls.

Myelination was evaluated with anti-myelin basic protein (MBP; BioLegend, 808401), anti-proteolipid protein (PLP; Abcam, AB28486), and anti-myelin ODC glycoprotein (MOG; Millipore, MAB5680) antibodies, with a slightly modified protocol. Briefly, brain sections were stained in a free-floating condition (to have maximum antibody penetration) in a 96-well plate. The sections were incubated with blocking buffer (5\% FBS and 2\% Triton X-100 in $1 \times$ PBS) for $2 \mathrm{~h}$ at room temperature. Then, primary antibodies were diluted in the same blocking buffer and the sections were incubated with diluted antibodies for $2 \mathrm{~h}$ at room temperature. Following primary antibody incubation, the brain sections were washed using $1 \times$ PBS three times, $5 \mathrm{~min}$ per wash. After the PBS washes, secondary antibodies were diluted in the same blocking buffer and incubated for $2 \mathrm{~h}$ at room temperature, followed by washing and then counterstaining with DAPI (Sigma-Aldrich, D9542-1MG). Brain sections were mounted with Fluoromount G (SouthernBiotech, 010001). An epifluorescence microscope (Zeiss Imager M2; Neurolucida 2018 by MBF Bioscience) was used to acquire images. A 20x air lens was used to collect images. To collect full-scale images, a contour containing the entire brain section was drawn, and the brain sections were focused at multiple locations to have the entire section focused. For imaging intensity analysis, the "measure" option of ImageJ software was used to quantify staining intensity. Data are presented as percentage of wild-type. Three comparable sections were stained and imaged for each animal, and thus $18 \mathrm{im}-$ ages in total were imaged and quantified for each group.

For staining with anti-Olig2 (Millipore, AB9610) and antiCC-1 (CalBioChem, OP80-100UG) antibodies, tissue sections were first processed via antigen retrieval. Antigen retrieval was achieved by heating $10 \mathrm{~mm}$ sodium citrate buffer $(\mathrm{pH} 6)$ in a container to boiling. The container was then removed from the heat source and glass slides containing the tissues were submerged in the warm buffer. The container was then put on a shaker with mild shaking. The slides were incubated for $20-25 \mathrm{~min}$. Postantigen retrieval, tissue slices were washed with $1 \times$ PBS three times, 5 min each. Then, tissue slices were incubated with blocking buffer $(2 \%$ goat serum $+1 \%$ Triton X-100 in $1 \times$ PBS) for at least $2 \mathrm{~h}$ at room temperature. The tissues were incubated with diluted primary antibodies in the same blocking buffer at $4^{\circ} \mathrm{C}$ overnight. After washing to remove the unbound primary antibody, the sections were incubated with secondary antibody for $2 \mathrm{~h}$ at room temperature, followed by washing, counterstaining, and mounting in Fluoromount G (SouthernBiotech, 0100-01). A confocal microscope (Zeiss LSM 880) and $25 \times$ water lens was used to collect images. To collect full-scale images, bounding grids were created. The grid was chosen to have the cortical layer directly above the corpus callosum and striatum. The z-layer was also added for image acquisition and a $15-\mu \mathrm{m}$ thick z-layer was chosen to image. The $z$-layer was chosen to have the maximum intensity. Images were taken at intervals of $1-\mu \mathrm{m}$ thickness. Following acquisition, czi files were processed for airyscan processing, stitching of tiles, and to have maximum intensity projection. In total, 18 images were acquired and quantified for each group. For cell counting of Olig2 $+/$ $\mathrm{CC} 1+$ cells, Image J software was used and the "analyze particles" option was used to count cells. Data are presented to show cells per $0.5 \mathrm{~mm}^{2}$.

The nodes of Ranvier (red) were positively stained for sodium channel using anti-Nav1.6, whereas the paranodes (green) that flank the nodes of Ranvier were labeled with anti-CASPR antibody. For tissue section staining with anti-Nav1.6 (Alomone labs, ASC-009) and antiCASPR (Neuromab, Clone K65/35, 75-001) antibodies, the tissue sections were first put through antigen retrieval as described above, followed by blocking and permeabilization with blocking buffer (5\% goat serum and $0.5 \%$ Triton X-100 in $1 \times$ PBS) for at least $2 \mathrm{~h}$ at room temperature. Tissues were then incubated with primary antibodies diluted in the same blocking buffer for $48 \mathrm{~h}$ at $4^{\circ} \mathrm{C}$, followed by incubation with the secondary antibodies. Confocal images were acquired with a $63 \times$ oil lens. Zstack images of $4 \mu \mathrm{m}$ thick were taken at $0.20-\mu \mathrm{m}$ intervals. Images were processed by using ZEN Black 2.3. For each animal, one section was stained and three different single images were taken for the cortical and corpus callosum regions. The length of the nodes of Ranvier was quantified using Imaris software. Maximum Intensity-projected czi images that were acquired from confocal microscopy were uploaded to the Imaris software. The length of the nodes was calculated automatically. The list of all sizes of node length calculated from Imaris was downloaded and used to calculate the average length and length distribution.

\section{Primary microglia culture}

One- or 2-d-old pups were genotyped and their forebrains were dissected in dissection buffer (5\% FBS in $1 \times$ PBS). The brains were then minced with sterilized razor blades and filtered through a sterile $40-\mu \mathrm{m}$ filter. Cell suspensions were then pelleted by centrifuging for $5 \mathrm{~min}$ at $300 \times \mathrm{g}$. The cells were then resuspended in 15 
$\mathrm{ml}$ of culture medium (DMEM $+10 \%$ FBS $+1 \%$ pen/ strep) and plated in a $75-\mathrm{mm}^{2}$ flask. Two days after plating, M-CSF was added to the culture medium at $5 \mathrm{ng} /$ $\mathrm{ml}$. The culture medium was replaced every $2 \mathrm{~d}$, and cells were allowed to grow for 12-14 d postseeding. To harvest microglia, flasks were shaken at $125 \mathrm{rpm}$ for $4-5 \mathrm{~h}$ at $37^{\circ} \mathrm{C}$. Detached microglia were then collected, pelleted by centrifuging for $5 \mathrm{~min}$ at $300 \times \mathrm{g}$. Cells were resuspended in culture medium, counted, and plated in poly-D-lysine-coated 12-well plates or 35-mm dishes. Microglia cells were allowed to attach to the plate surface for $1 \mathrm{~h}$ at $37^{\circ} \mathrm{C}$. Following $1 \mathrm{~h}$ of incubation, unattached cells were washed away. Cells in $35-\mathrm{mm}$ dishes were allowed to grow for 2-3d and used for the in vitro phagocytosis assay.

\section{In vitro phagocytosis assay}

Primary microglial cells were cultured in $35-\mathrm{mm}$ dishes according to the protocol described above. pHrodo Green zymosan bioparticles, dissolved at $0.5 \mathrm{mg} / \mathrm{ml}$ in phenol red-free DMEM, were used for this assay. Cell culture medium containing phenol red was removed immediately before live-cell imaging and was replaced with $100 \mu \mathrm{l}$ of phenol red-free DMEM containing pHrodo Green zymosan bioparticles. The microscope-stage incubator was set at $37^{\circ} \mathrm{C}$ and the $\mathrm{CO}_{2}$ level was set at $5 \%$. A confocal microscope (Zeiss LSM 880 ) was used to acquire images. A $63 \times$ oil lens was used to collect images. A series of images was collected in 60-s intervals for $60 \mathrm{~min}$. Acquired czi images were processed by using ZEN Blue 2.3. A sample size of $n=4$ was used for each mouse type.

\section{Seizure induction via pilocarpine}

Pilocarpine was used to induce status epilepticus (SE). Mice 8-10 weeks of age were weighed and intraperitoneally injected with methyl scopolamine at $1 \mathrm{mg} /$ $\mathrm{kg}$ in $0.9 \% \mathrm{NaCl}$. Animals were allowed to rest and roam around in their cages for $10 \mathrm{~min}$ to allow the scopolamine to take effect by blocking peripheral cholinergic receptors. Pilocarpine was dissolved in $0.9 \% \mathrm{NaCl}$ and injected intraperitoneally into each mouse at a dose of $200 \mathrm{mg} / \mathrm{kg}$ for the first dose; the subsequent doses were applied at $15-\mathrm{min}$ intervals at $50 \mathrm{mg} / \mathrm{kg}$ until each animal began to show seizure behaviors considered to be stage 4 or 5 of the Racine scale. Animals were allowed to have seizures for $4 \mathrm{~h}$ before being injected with Diazepam ( $5 \mathrm{mg} / \mathrm{kg}$; dissolved in $12 \%$ ethanol) to terminate the seizures. Animals were kept on a heatpad to minimize suffering and to allow for a higher yield. For sample sizes, 23 littermate controls (10 M, $13 \mathrm{~F})$ and 22 ATG7KO mice (12 M, $10 \mathrm{~F}$ ) were injected according to the protocol above.

\section{Seizure induction via kainic acid}

Animals were anesthetized by using $4 \%$ isoflurane vapor, and anesthesia was confirmed by pinching a toe and looking for an absence of reflex. $100 \mu \mathrm{l}$ of bupivacaine was injected under the forebrain skin before proceeding with surgery. Eye lubricant was also applied to prevent the eyes from drying out. Following anesthesia, animals were stereotaxically injected with $100 \mathrm{nl}$ of kainic acid (20 or $50 \mu \mathrm{m}$ ). Animals were injected at the dorsal hippocampus region and the following coordinates from bregma were used: anteroposterior -2 , mediolateral +1.5 , dorsoventral -2 . After the injection, the syringe was kept in for an additional 30-60 s to avoid backflow of the volume. Animals were returned to their home cage and their status of seizure development was monitored. For sample sizes, six littermate controls (three $M$, three $F$ ), and six ATG7KO (three $M$, three F) mice for each of the 20 and $50 \mu \mathrm{m}$ experiments were injected according to the protocol above.

\section{Seizure induction via kindling}

The surgical procedure described above was conducted to implant electrodes in the amygdala of each animal. The following coordinates were used: anteroposterior -1.2 , mediolateral +3.1 , dorsoventral -3.7 . Two additional recording electrodes were implanted epidurally on the cortex on both the ipsilateral and contralateral sides. All electrodes were fixed with dental cement. Mice were allowed to recover for at least $7 \mathrm{~d}$ postsurgery before being subjected to kindling. Mice were kept in their home cages and were allowed to roam freely during the kindling procedures. Mice were hooked to a Grasso S88 stimulator device. The kindling procedure was adapted from Morales et al. (2014). To identify the after-discharge threshold (ADT), current intensity was started at $10 \mu \mathrm{A}$ and gradually increased by a factor of 1.25 every $10 \mathrm{~min}$ until the appearance of the first after-discharge, which is defined as electrical waves between $1-8 \mathrm{~Hz}$ and lasting a minimum of $5 \mathrm{~s}$. Stimulus intensity was $1 \times$ ADT. Mice were subjected to kindling for three consecutive days, and each day the animals received 10 stimulations with 20 -min intervals between stimulations. Stimulations were $10 \mathrm{~s}$ long and the train frequency was $50 \mathrm{~Hz}$ (biphasic). After concluding the tests, mouse brains were fixed and sectioned for cresyl violet staining for histologic verification of electrode placement. Animals with a correct electrode placement in the right basolateral amygdala were used in subsequent data analyses.

\section{Behavior tests}

Animal behavioral tests were performed in the Behavior Core of Albany Medical College. The animals were between eight and 10 weeks of age at the time of testing. The open field test (OFT) was used to measure the motor activity of animals by measuring the distance the animals traveled. Mice were brought into the OFT room at least 30 min before the OFT to allow them to acclimate to the room/environment. The apparatus that was used is a white cubical container divided into four $50 \mathrm{~cm}^{2}$ chambers, which allowed four mice to be tested at once. OFT was conducted under a dim, red light environment (50 lux) 
Table 1: Antibodies

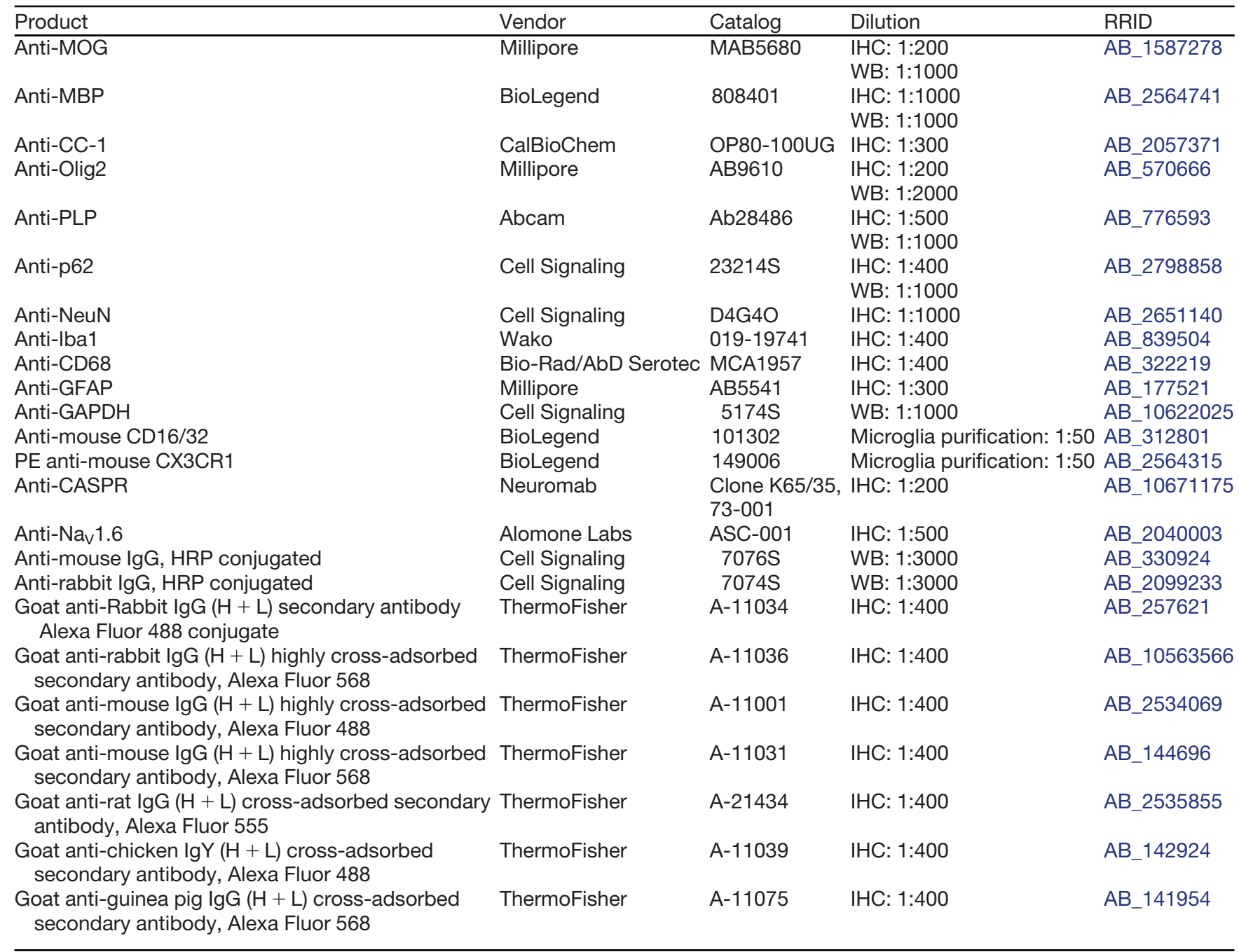

to allow the mice to roam and explore freely and their motor activity to be measured. ANY-maze 5.3 software was used to collect data; the program collected data on total distance traveled as well as time spent moving/average speed. The experiment lasted for $5 \mathrm{~min}$ for each animal and the OFT apparatus was cleaned with $70 \%$ ethanol and allowed to dry in between testing different animals. Sample sizes of 23 littermate controls (10 M, $13 \mathrm{~F}$ ) and 22 ATG7 ${ }^{\text {Cx3cr1-creCKO }}$ mice $(12 \mathrm{M}, 10 \mathrm{~F})$ were tested. For rotarod test, mice were brought into the rotarod testing room at least $30 \mathrm{~min}$ before the test to allow them to acclimate to the room/environment. The test was conducted for five consecutive days and the tests were given at the same time every day. For the training period, animals were placed on the rotarod and trained at a fixed speed of $4 \mathrm{rpm}$. Then the animals were returned to their home cage for at least $10 \mathrm{~min}$, and this step was repeated another two times. In between testing different animals, the rotarod was wiped and cleaned with $70 \%$ ethanol, and fecal pellets were removed. For the testing period, the rotarod was set to accelerate every $20 \mathrm{~s}$ by $1 \mathrm{rpm}$ and the initial speed was $4 \mathrm{rpm}$. The exact speed and time a mouse fell from the rod was recorded. A mouse was given three trials per day and the per-day average was used to calculate the data.

\section{Statistical analysis}

All data collected and presented were subjected to statistical analysis using GraphPad Prism7 software or estimation stats (free online version). Appropriate tests were applied for comparisons between control and ATG7KO mice. Estimation stats was used to test the significance of differences between the control and ATG7KO groups. Twoway ANOVA with repeated measures was used for the comparison of the time course for the latency to fall in the rotarod test between the control and ATG7KO groups. Data are shown as mean \pm SEM. Log-rank (Mantel-Cox) test was used for statistical analysis of survival rate; $p<0.05$ was considered to be significant All key resources related to the experimental procedures are listed in Tables 1Tables 5. 
Table 2: Reagents and other materials

\begin{tabular}{|c|c|c|c|}
\hline Product & Vendor & Catalog no. & RRID \\
\hline Neg-50 & ThermoScientific & 6502 & \\
\hline Fluoromount G & SouthernBiotech & 0100-01 & \\
\hline DAPI & Sigma-Aldrich & D9542-1MG & \\
\hline DMEM & Corning & $10013-\mathrm{CV}$ & \\
\hline Phenol red-free DMEM & Life technologies & 31053-028 & \\
\hline DMEM/F12 & Gibco & $11039-021$ & \\
\hline Mouse M-CSF & Shenandoah & $200-08$ & \\
\hline Percoll & GE Healthcare & $17-0891-01$ & \\
\hline Papain & Sigma & P3125 & \\
\hline Dispase II & Stemcell & 07913 & \\
\hline DNase I & Sigma & D4263 & \\
\hline Bovine serum albumin & Sigma & A7030 & \\
\hline Fetal bovine aerum & Atlanta Biologicalalals & $\mathrm{S} 11150 \mathrm{H}$ & \\
\hline Penicillin/streptomycin & Cellgro & $30-008-\mathrm{Cl}$ & \\
\hline Poly-D-lysine & Sigma & P6407-5MG & \\
\hline PowerUP SYBR Green Master Mix & ThermoFisher & A25777 & \\
\hline TRIzol & Life Technologies & 15596018 & \\
\hline Verso cDNA synthesis kit & ThermoFisher & $A B 1453 B$ & \\
\hline Pierce BCA Protein Assay kit & ThermoScientific & 23225 & \\
\hline Chemiluminescent Substrate & ThermoScientific & 34580 & \\
\hline pHrodo Green Zymosan Bioparticles Conjugate for Phagocytosis & ThermoFisher & P35365 & \\
\hline Falcon $40 \mu \mathrm{m}$ Cell Strainer & Corning & 352340 & \\
\hline Preseparation Filters $(30 \mu \mathrm{m})$ & Miltenyi & $130-041-407$ & \\
\hline MS Columns & Miltenyi & $130-042-201$ & \\
\hline Pilocarpine & Sigma & P6503 & \\
\hline
\end{tabular}

Table 3: Primers for qPCR

\begin{tabular}{llll}
\hline Gene & Sense $\left(5^{\prime}-3^{\prime}\right)$ & Anti-sense $\left(3^{\prime}-5^{\prime}\right)$ & Species \\
\hline TNF- $\alpha$ & ATGGCCTCCCTCTCATCAGT & GTTTGCTACGACGTGGGCTA & Mouse \\
IL-1 $\beta$ & CGCAGCAGCACATCAACAAG & GTGCTCATGTCCTCATCCTG & Mouse \\
IL6 & ACCAGAGGAATTTCAATAGGC & TGATGCACTTGCAGAAACA \\
IFN- $\alpha$ & GGACTTTGGATTCCCGCAGGAGAAG & GCTGCATCAGACAGCCTTGCAGGTC \\
IFN- $\beta$ & TCCGAGCAGAGATCTTCAGGAA & TGCAACCACCACTCATTCTGAG & Mouse \\
IFN- $\gamma$ & GCTCTGAGACAATGAACGCT & AAAGAGATAATCTGGCTCTGC & Mouse \\
iNOS & TGGAGCGAGTTGTGATTGTC & CCAGTAGCTGCCGCTCTCAT & Mouse \\
GAPDH & GACAACTTTGGCATTGTGG & ATGCAGGGATGATGTTCTG & Mouse
\end{tabular}

Table 4: Primers for genotyping

\begin{tabular}{lll}
\hline Gene & Sense $\left(5^{\prime}-3^{\prime}\right)$ & Anti-sense (3'-5') \\
\hline Cx3cr1 Cre $+/-$ & TTGCCTGCATTACCGGTCGAT & GATCCTGGCAATTCGGCTAT \\
ATG7 flox $-373 \mathrm{bp}$ & ACAGTGCACATCCTGTTCCA & CCAAAGGAAACCAAGGGAGT \\
ATG7 flox $-243 \mathrm{bp}$ & GGACTTGTGCCTCACCAGAT & CTCGTCACTCATGTCCCAGA \\
TSC1 flow & GTCACGACCGTAGGAGAAGC & GAATCAACCCCACAGAGCAT \\
\hline
\end{tabular}

Table 5: Software

\begin{tabular}{lll}
\hline Product & Developer & Webpage \\
\hline ImageJ & NIH & https://imagej.nih.gov/ij/ \\
GraphPad Prism 7.0 & GraphPad Software & https://graphpad.com \\
ZEN Black & Zeiss & https://zeiss.com \\
ZEN Blue & Zeiss & https://zeiss.com \\
Sirenia Acquisition & Pinnacle Technologies, Inc. & https://www.pinnaclet.com/sirenia.html \\
Neurolucida & MBF Bioscience & https://mbfbioscience.com \\
Imaris & Bitplane & https://imaris.oxinst.com/
\end{tabular}


A

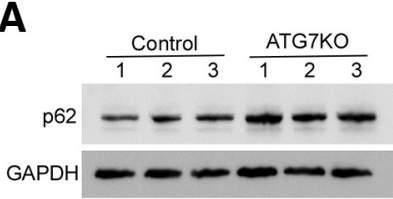

C
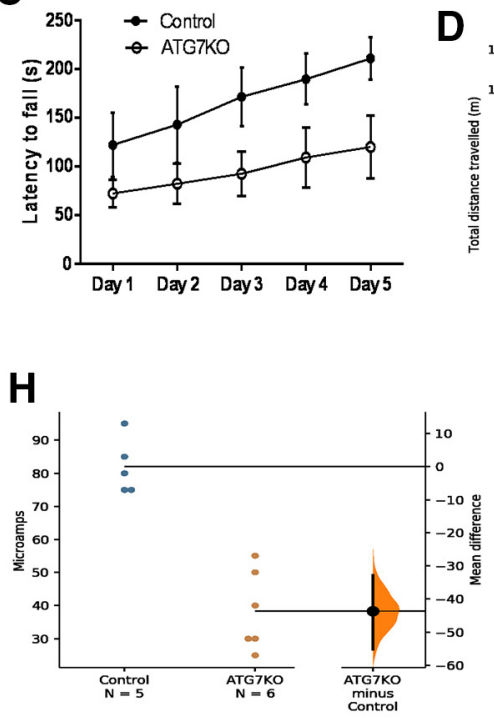

J

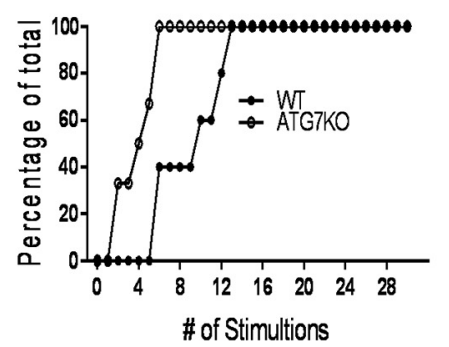

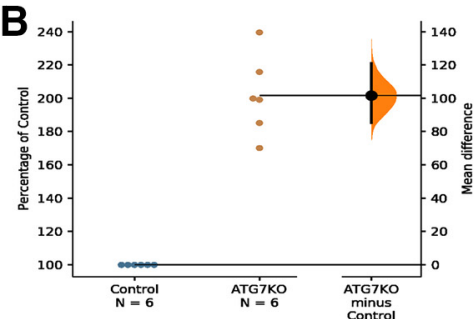

D

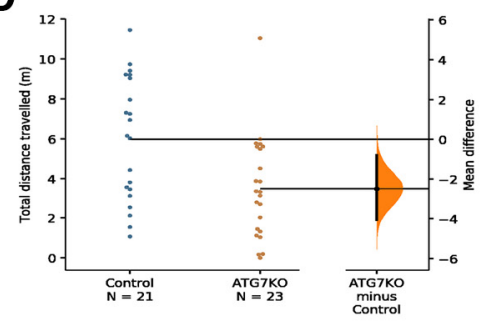

E

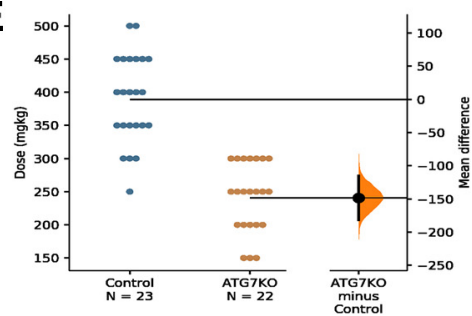

$\mathbf{F}$

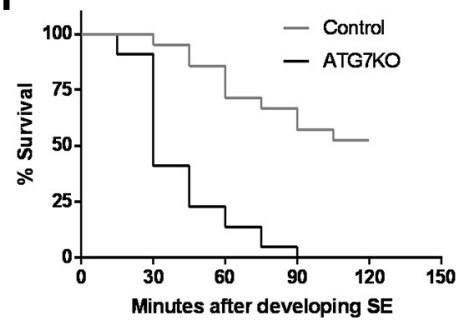

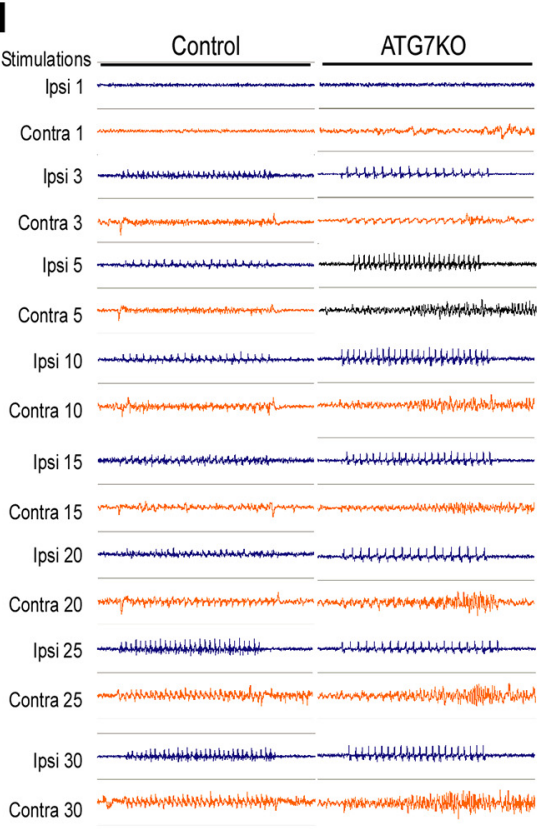

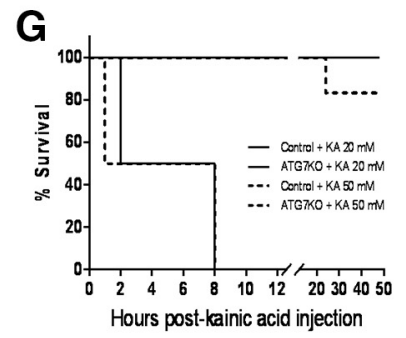

$\mathbf{L}$
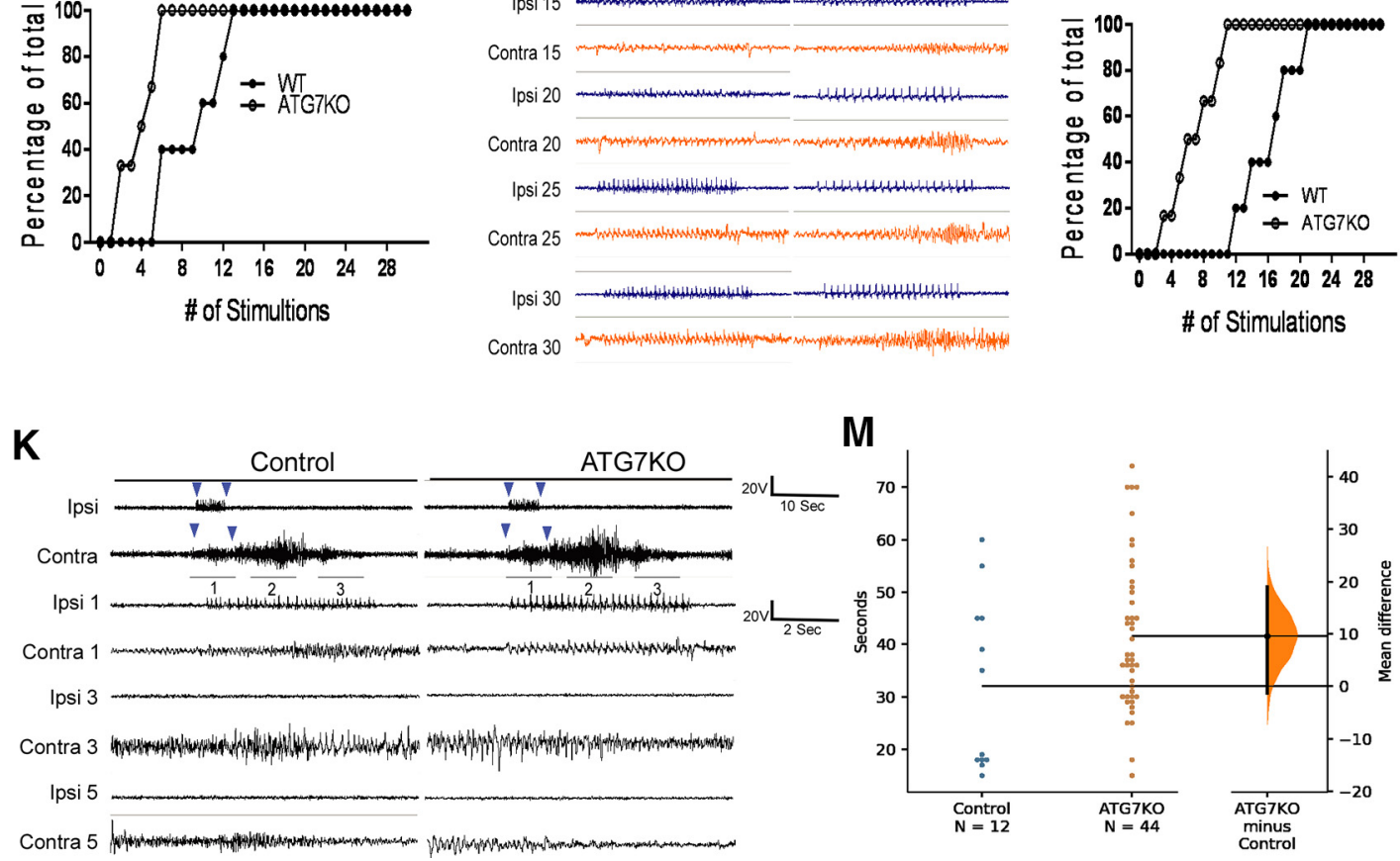

Figure 1. Impact of deletion of ATG7 in microglia on seizure susceptibility. $\boldsymbol{A}$, Western blot analysis of p62 in ATG7KO mice and their littermate controls. B, Quantification of p62 protein levels in ATG7KO mice and their littermate controls; $n=6$ (3 M, $3 \mathrm{~F})$. The unpaired mean difference (hereafter referred to as UMD) between control and ATG7KO is $1.02 \mathrm{e}+02(95.0 \% \mathrm{Cl} 85.1,1.21 \mathrm{e}+02)$. The $p$ value of the two-sided permutation $t$ test (hereafter referred to as $p_{t}$ ) is 0.0008 . C , Quantification of latency to fall in the rotarod test in 21 littermate control (11 M, $10 \mathrm{~F})$ and 23 ATG7KO mice (10 M, $13 \mathrm{~F})$. Two-way ANOVA with repeated measures; group effect: $F_{(4,110)}=63.46, p<0.0001$; time effect: $F_{(4,110)}=294.1, p<0.0001$; interaction: $F_{(4,110)}=3.104, p=0.0184(C l=95 \%) . D$, Quantification of total distance traveled in the OFT in 21 littermate control (11 M, $10 \mathrm{~F}$ ) and 23 ATG7KO mice (10 M, $13 \mathrm{~F})$. UMD: $-2.48(95.0 \% \mathrm{Cl}-4.05,-0.791) ; p_{\mathrm{t}}=0.0068$. $E$, Pilocarpine doses to induce SE in in 23 control (10 M, $\left.13 \mathrm{~F}\right)$ and $22 \mathrm{ATG} 7 \mathrm{KO}(12 \mathrm{M}$, 
continued

10 F) mice. UMD: $-1.48 \mathrm{e}+02(95.0 \% \mathrm{Cl}-1.82 \mathrm{e}+02,-1.15 \mathrm{e}+02) ; p_{\mathrm{t}}=0.0$. $\boldsymbol{F}$, Percentage of control and ATG7KO mice surviving SE induced by pilocarpine in 23 control $(10 \mathrm{M}, 13 \mathrm{~F})$ and 22 ATG7KO (12 M, $10 \mathrm{~F})$ mice. Log-rank (Mantel-Cox) test: $p<0.0001$. G, Percentage of control and ATG7KO mice surviving SE induced by kainic acid $(0.5 \mu \mathrm{l}$ of 20 and $50 \mu \mathrm{m})$ injected into the dorsal dentate gyrus of the hippocampus; $n=6(3 \mathrm{M}, 3 \mathrm{~F}$ ). Log-rank (Mantel-Cox) test: $p=0.0009$ between control+KA 20 mM and ATG7KO+KA $20 \mathrm{~mm} ; p=0.0009$ between control+KA $50 \mathrm{~mm}$ and ATG7KO+KA $50 \mathrm{~mm}$. $\boldsymbol{H}$, After-discharge threshold in control and ATG7KO mice subjected to kindling. UMD: $-43.7[95.0 \% \mathrm{Cl}-55.2,-32.8] ; p_{\mathrm{t}}: 0.0$. I, Representative epidural recordings of electrical activities in ipsilateral and contralateral sides. $\boldsymbol{J}$, Numbers of stimulations needed to elicit contralateral activities in control and ATG7KO mice. Two-way ANOVA; group effect: $F_{(30,30)}=7.336, p<0.0001$; number of stimulation effect: $F_{(1,30)}=14.43, p=0.0007 . K$, Representative EEG traces of animals that developed generalized seizures because of kindling. $\boldsymbol{L}$, Numbers of stimulations needed to trigger generalized seizures in control and ATG7KO mice. Two-way ANOVA; group effect: $F_{(30,30)}=5.3, p<0.0001$; number of stimulation effect: $F_{(1,30)}=26.28, p<0.0001$. $M$, Average seizure duration in control and ATG7KO mice. UMD: $9.55(95.0 \% \mathrm{Cl}$ $-1.34,19.0) ; p_{\mathrm{t}}=0.0506$.

\section{Results}

\section{ATG7KO mice display increased seizure susceptibility and high mortality from seizures}

The ATG7KO line with ATG7 deletion in microglia was generated by crossing $A T G 7^{f / f}$ mice (McMahon et al., 2012) with the Cx3cr1-cre line that was recently demonstrated to be microglia specific (Zhao et al., 2019). Western blot analysis revealed that deletion of ATG7 results in accumulation of p62 (Fig. 1A,B), a marker of autophagy inactivity (Friedman et al., 2012; McMahon et al., 2012), confirming that autophagy activity is suppressed. Most ATG7KO mice are born without obvious abnormalities and can live for $>12$ months. None of the ATG7KO mice developed spontaneous seizures (data not shown). However, we observed two mice out of 43 that displayed marked locomotor impairment (data not shown). These two mice showed loss of postural control and hardly moved by the age of weaning, and they were humanely euthanized. Accordingly, we performed rotarod test and OFT on a cohort of ATG7KO mice to evaluate general motor behaviors. We observed that ATG7KO mice fell more easily from the rotarod onto the platform in rotarod tests and traveled shorter distances in OFTs compared with wild-type littermates (Fig. 1C,D). We next determined whether ATG7KO mice are more susceptible to developing spontaneous seizures in the pilocarpine model of temporal lobe epilepsy. Mice were treated with a single dose of pilocarpine at $200 \mathrm{mg} / \mathrm{kg}$ followed by $50 \mathrm{mg} / \mathrm{kg}$ every $10 \mathrm{~min}$ via intraperitoneal injection until they developed SE. The induction of SE in ATG7KO mice required less than half the dose needed in the control mice (Fig. 1E). In the littermate control group, over $50 \%$ of the mice survived $2 \mathrm{~h}$ of SE. However, ATG7KO mice became very sensitive to pilocarpine-induced SE. More strikingly, all ATG7KO mice died within 30-90 min after induction of SE (Fig. 1F). To exclude any potential systemic effect from pilocarpine treatment, we employed another SE model established using intracranial hippocampal injection of kainic acid (Fig. 1G). In this model, nearly $80 \%$ of the control mice survived SE. However, all ATG7KO mice died from seizures. These data suggest that ATG7KO mice are very susceptible to developing severe, generalized fatal seizures induced by pilocarpine or kainic acid.

We next employed an electric amygdala kindling model (Goddard et al., 1969; Sato et al., 1990). The seizures evoked in this model are moderate and brief, which helps to better evaluate the difference in seizure susceptibility between control and ATG7KO mice. We examined whether ATG7KO animals are prone to evoked seizures and whether after-discharges can readily propagate to the contralateral hemisphere, a process underlying the development of generalized seizures. We implanted a pair of electrodes into the right amygdala and two further electrodes epidurally on the ipsilateral and contralateral cortices for recording the propagation of electrical activities evoked by amygdala stimulation. We found that the intensity of electric currents required to elicit after-discharge in ATG7KO mice was $\sim 50 \%$ of that needed in control mice, consistent with increased neuronal excitability in the former (Fig. $1 H$ ). Animals were subjected to a rapid kindling protocol with 10 trains of stimulations with 20-min intervals daily for three consecutive days (Morales et al., 2014). The amygdala stimulation evoked an equally large amplitude of electrical activities in the ipsilateral cortex in both control and ATG7KO mice (Fig. 1/). Amygdala stimulation also evoked electrical activities in the contralateral cortex in all ATG7KO mice after four to five trains of stimulation (Fig. 1J). However, only very small-amplitude and short-lived electrical activities were evoked in the control animals during the 10 trains of repeated stimulations (Fig. 1J). Moreover, amygdala stimulation triggered the onset of stage four to five generalized behavioral seizures (Fig. $1 K-M)$ in all ATG7KO mice within the first 10 trains of stimulation, whereas nearly double the number of stimulations was required in the control mice. These data suggest that seizure induction from amygdala stimulation as well as contralateral propagation of seizures is markedly increased in ATG7KO mice. Taken together, we demonstrated that ATG7KO mice display increased susceptibility to developing severe generalized seizures and high comortality.

\section{The impact of microglial autophagy deficiency on microglia, astrocytes, and neurons}

We did not find any difference in the density of microglia in the cortex and hippocampus of ATG7KO mice compared with controls (Fig. $2 A-C$ ). CD68 is a lysosomal protein. The level of CD68 expression is nearly undetectable in microglia of normal brain, but is frequently induced following seizures and other neurologic disorders (Hopperton et al., 2018; Zhao et al., 2018). We did not detect any induction of CD68 in ATG7KO microglia (Fig. 
A

Cortex
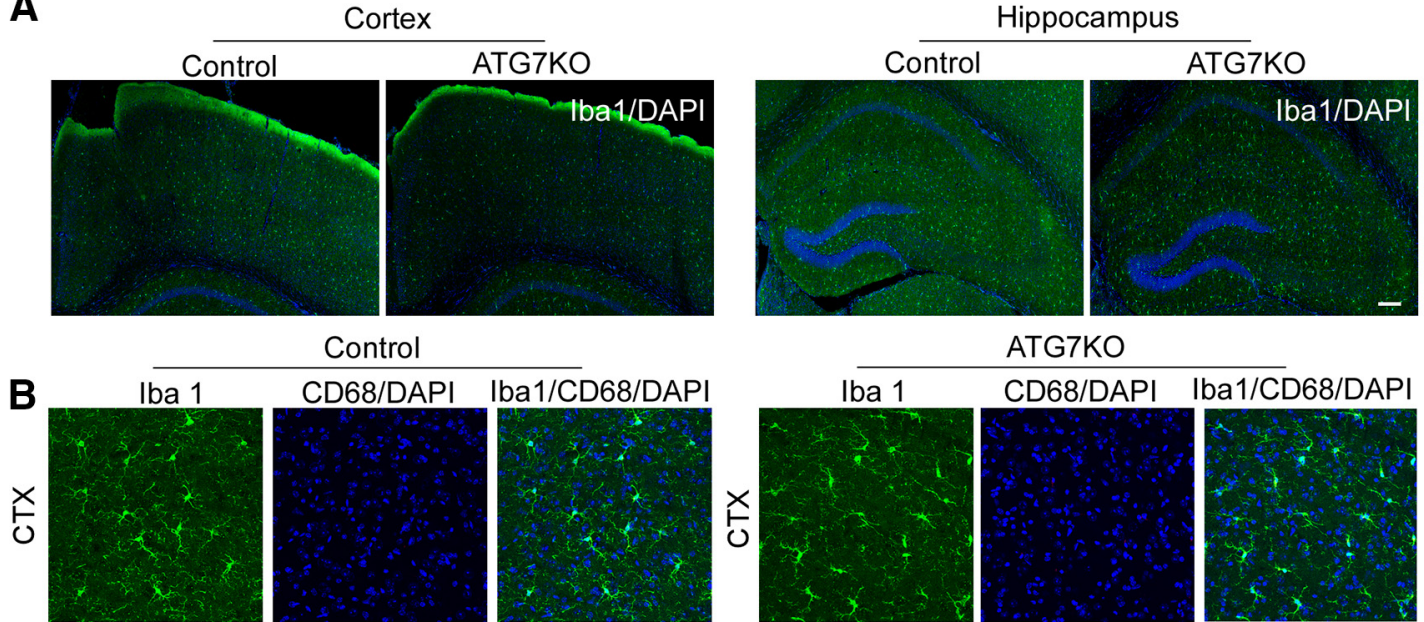

Control

ATG7KO
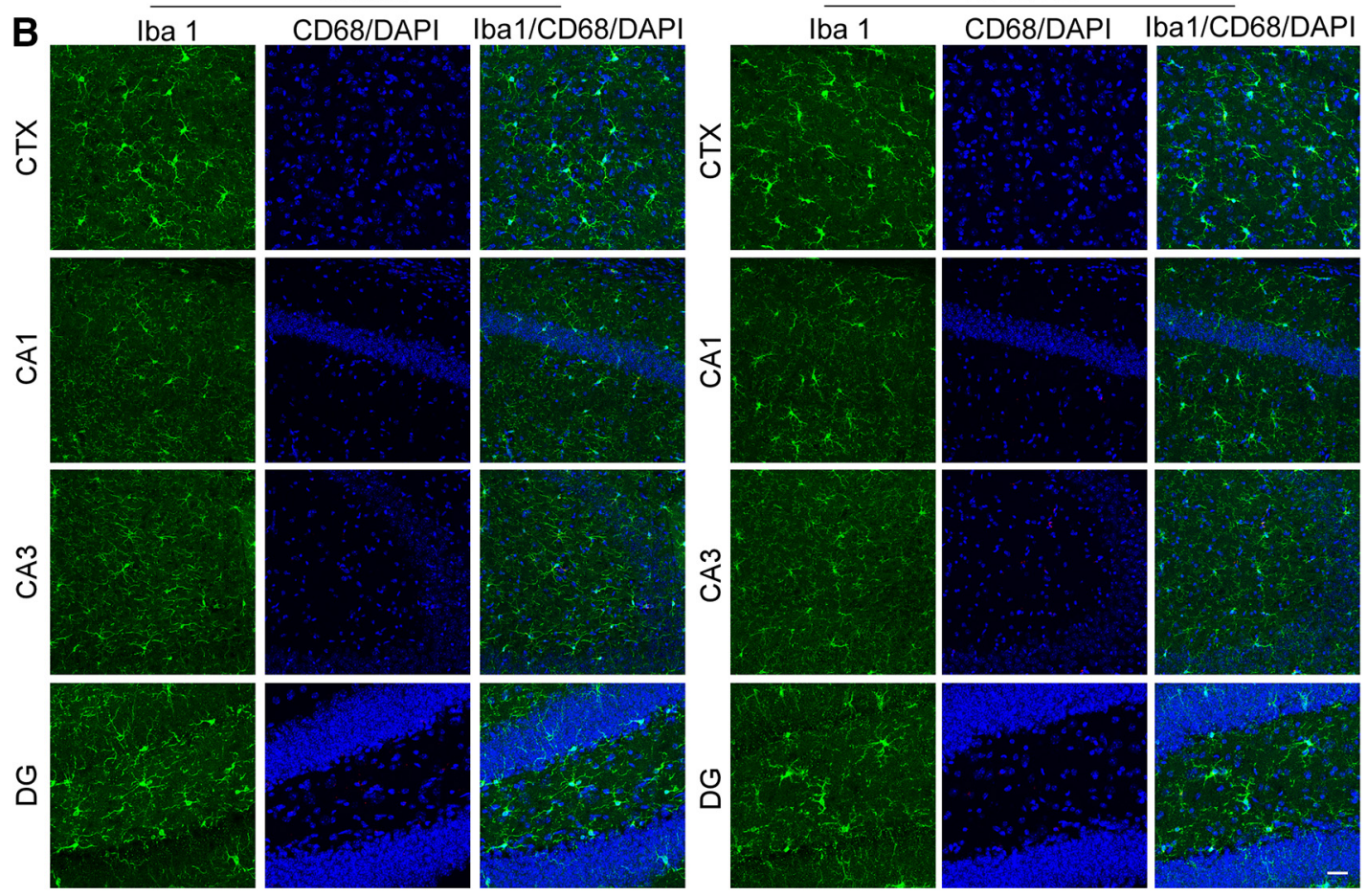

c

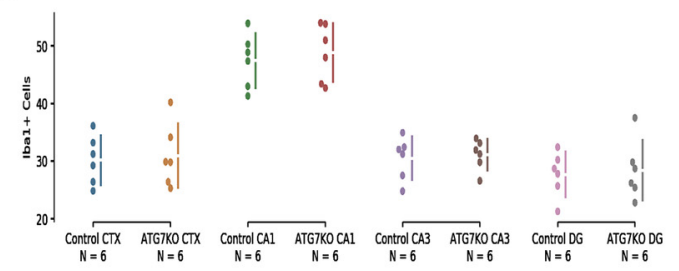

D
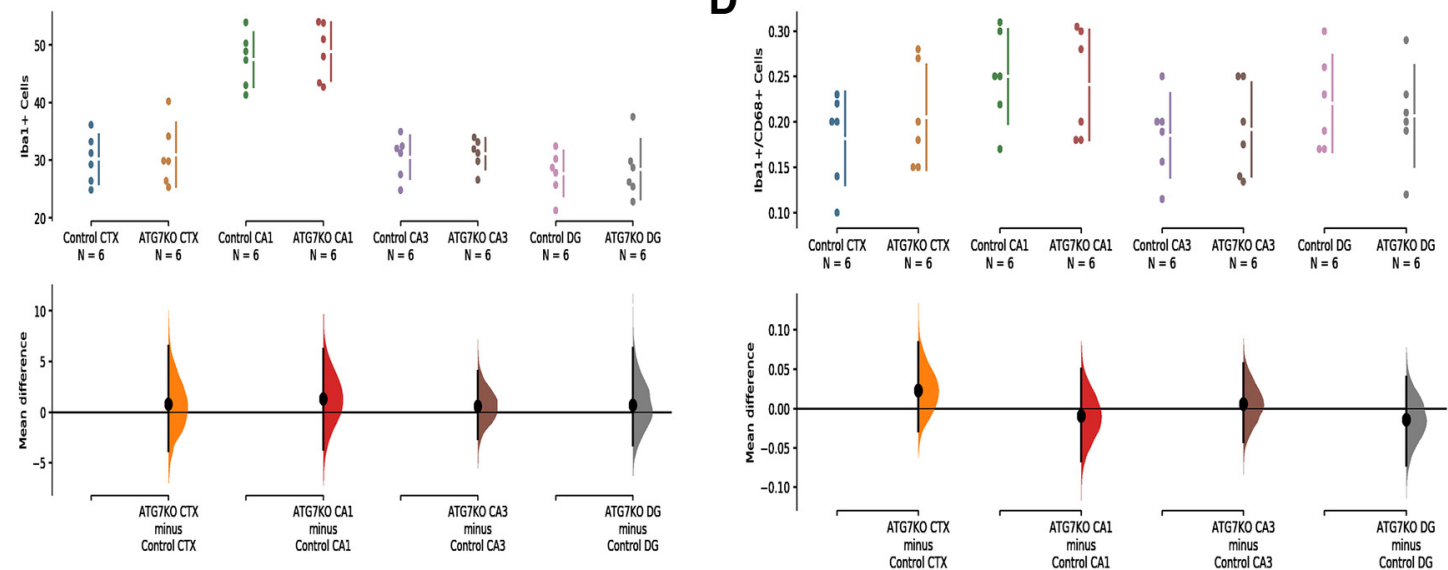

Figure 2. The impact of ATG7 deletion on microglia. $\boldsymbol{A}$, Full-montage images of $\mathrm{lba} 1^{+}$cells in the cortical and hippocampal areas in control and ATG7KO mice. Scale bar: $200 \mu \mathrm{m}$. Green: anti-lba1; blue: DAPI. B, Confocal images $(25 \times)$ of microglia from the cortical (CTX) and hippocampal CA1, CA3, and DG regions of control and ATG7KO mice. Scale bar: $20 \mu \mathrm{m}$. Green: anti-Iba1; red: antiCD68; blue: DAPI. $\boldsymbol{C}$, Quantification of lba1 ${ }^{+}$cells per $10^{5} \mu \mathrm{m}^{2}(n=6 ; 3 \mathrm{M}, 3 \mathrm{~F})$. CTX: UMD: $0.789(95.0 \% \mathrm{Cl}-3.81,6.49) ; p_{\mathrm{t}}=0.788$. CA1: UMD: $1.35(95.0 \% \mathrm{Cl}-3.65,6.21) ; p_{\mathrm{t}}=0.62$. CA3: UMD: $0.617(95.0 \% \mathrm{Cl}-2.59,4.02) ; p_{\mathrm{t}}=0.747 . \mathrm{DG}: \mathrm{UMD}: 0.717(95.0 \% \mathrm{Cl}$ $-3.22,6.28) ; p_{\mathrm{t}}=0.797 . \boldsymbol{D}$, Quantification of $\mathrm{CD} 8^{+} / \mathrm{lba} 1^{+}$cells per $10^{5} \mu \mathrm{m}^{2}(n=6 ; 3 \mathrm{M}, 3 \mathrm{~F})$. CTX: UMD: $0.0233(95.0 \% \mathrm{Cl}-0.0283$, $0.0833) ; p_{\mathrm{t}}=0.448$. CA1: $-0.009(95.0 \% \mathrm{Cl}-0.0665,0.0503) ; p_{\mathrm{t}}=0.786$. CA3: UMD: $0.0065(95.0 \% \mathrm{Cl}-0.0418,0.057) ; p_{\mathrm{t}}=0.806$. DG: UMD: $-0.0133(95.0 \% \mathrm{Cl}-0.0717,0.04) ; p_{\mathrm{t}}=0.68$. 
$2 B, D)$. We next analyzed cytokine expression. There was no difference in the expression levels of TNF $\alpha$, IL1 $\beta$, IL6, IFNs, and iNOS in cortical lysates (Fig. $3 A$ ), and only a moderate elevation ( 2-3-fold) in hippocampal lysate or purified microglia (Fig. 3B,C). Microglia are the main phagocytotic cells (Zhao et al., 2018). We performed a phagocytosis analysis in cultured microglia prepared from ATG7KO and control mice. We did not detect any significant change in phagocytosis activity of ATG7-deficient microglia compared with the control microglia (Fig. $3 D-F)$. Thus, microglial autophagy deficiency causes little, if any, change in density and morphology of microglia or phagocytotic activity. We next evaluated the impact of autophagy-deficient microglia on astrocytes and neurons in ATG7KO mouse brain. We did not observe any significant increase in astrocytes in the cortex and hippocampus (Fig. 4A,C,E), nor any effect on the density of neurons (Fig. 4B,D,F).

\section{Microglial autophagy deficiency leads to increased myelination and size of the nodes of Ranvier}

Recent studies strongly suggest that microglia regulate ODC density and perhaps myelination (Miron, 2017; Wlodarczyk et al., 2017; Lloyd and Miron, 2019). Accordingly, we examined myelination markers in ATG7KO mice. Immunohistological analysis revealed a significant increase in MBP, along with markers of myelination (MOG and PLP) in the corpus callosum, cingulate cortex and striatum, regions where axons are heavily myelinated (Fig. $5 A, B$ ). Western blottings confirmed the increased levels of these myelination markers in ATG7KO mouse brains (Fig. 5C-E).

To understand how microglial deficiency of autophagy leads to increased myelination markers, we evaluated total ODCs and mature myelin-producing ODCs. Olig2 is expressed by ODCs in most stages of ODC development, whereas CC1 expression is more restricted to mature, myelin-producing ODCs. IHC revealed a significant increase in both Olig2-positive and CC1-positive populations in the corpus callosum, cingulate cortex, and striatum in ATG7KO mice (Fig. 6A-F). Western blottings also confirmed the increased levels of Olig2 in mouse brains (Fig. 6G,H). Together, these data suggest that suppression of microglial autophagy increases the amount of mature ODCs and myelination proteins.

The nodes of Ranvier mediate the stationary transmission of action potentials along axons. Recent studies reported that the size of the nodes of Ranvier is proportional to the speed of action potential transmission (Ford et al., 2015; Arancibia-Cárcamo et al., 2017). Lengthening of the node of Ranvier is strongly associated with altered function of the myelinated axon in several neurologic disorders (Arancibia-Cárcamo et al., 2017). Accordingly, we performed IHC to evaluate the nodes of Ranvier (using antisodium channel $\mathrm{Na}_{\vee} 1.6$ antibody) and the paranodes (using anti-CASPR antibody; Arancibia-Cárcamo et al., 2017). We detected a shift toward longer nodes of Ranvier in ATG7KO mouse brain (Fig. 7A-E). Taken together, these data suggest that the microglial autophagy regulates homeostasis of ODCs and myelination of axons.

\section{Discussion}

In the present study, we showed that ATG7KO mice with microglial autophagy deficiency are more susceptible to seizures as well as to developing severe generalized seizures resulting in death, compared with wild-type littermates. We further revealed that inhibition of autophagy in microglia disturbs ODC homeostasis in the CNS, leading to increased density of mature ODCs, elevated levels of myelination proteins, and increased size of the nodes of Ranvier. Our study revealed a critical role of microglial autophagy in regulating homeostasis of ODCs and seizure susceptibility.

\section{Role of autophagy in microglia}

Autophagy activity is regulated according to changes in physiological conditions, including growth factors, nutrient bioavailability, stress, and many others (Levine and Klionsky, 2004). In general, autophagy acts downstream of mTOR. Our previous study demonstrated that excessive activation of microglial mTOR in TSC1 deficiency mice causes marked proliferation of microglia and significant morphologic changes (Zhao et al., 2018). We found that deletion of microglial ATG7 has little effect on the density and morphology of microglia. This is in consistent with observations reported in a recent study (Choi et al., 2020). Our data also suggest that basal autophagy activity does not likely contribute to the changes in microglial properties seen in TSC1 deficiency mice (Zhao et al., 2018).

Autophagy regulates the innate immune response of macrophages and microglia (Sanjuan et al., 2007; Cunha et al., 2018; Samie et al., 2018; Mathur et al., 2019). Deficiency of autophagy in macrophages exacerbates the inflammatory response and causes autoimmune diseases (Mathur et al., 2019). Inhibition of autophagy is an essential step leading to activation of microglia and induction of proinflammatory cytokines following LPS treatment ( $\mathrm{He}$ et al., 2018). We found that under basal conditions, deficiency of autophagy leads to a very moderate increase in the levels of cytokines. It is unclear whether the mild elevation of cytokines is meaningful, and its biological significance needs to be determined in future studies. Microglia are the main phagocytotic cells in the CNS. Although previous studies suggest that autophagy regulates phagocytosis of microglia (Heckmann et al., 2019; Lee et al., 2019), the lack of effect on phagocytosis in our study may suggest the existence of both autophagy-dependent and -independent phagocytotic routes in microglia.

\section{Role of microglial autophagy in myelination}

A large body of studies has revealed that mTOR signaling has a profound role in regulating the development of ODCs and myelination (Meikle et al., 2007; Carson et al., 2012; Lebrun-Julien et al., 2014; Wahl et al., 2014; Jiang et al., 2016; Beirowski et al., 2017; Figlia et al., 2017). However, all these studies focused on modifying mTOR signaling directly either in neurons, ODCs or Schwann cells. More recently, microglia were reported to regulate ODC development and myelination (Miron et al., 2013; 
A
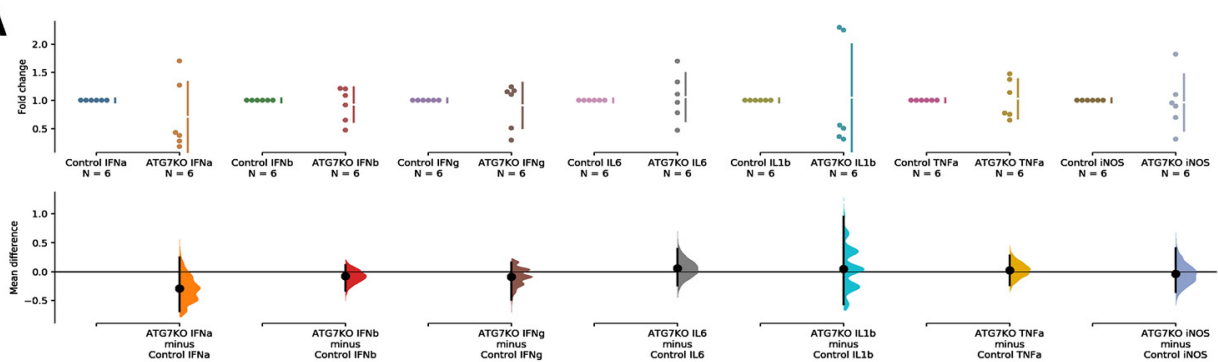

B

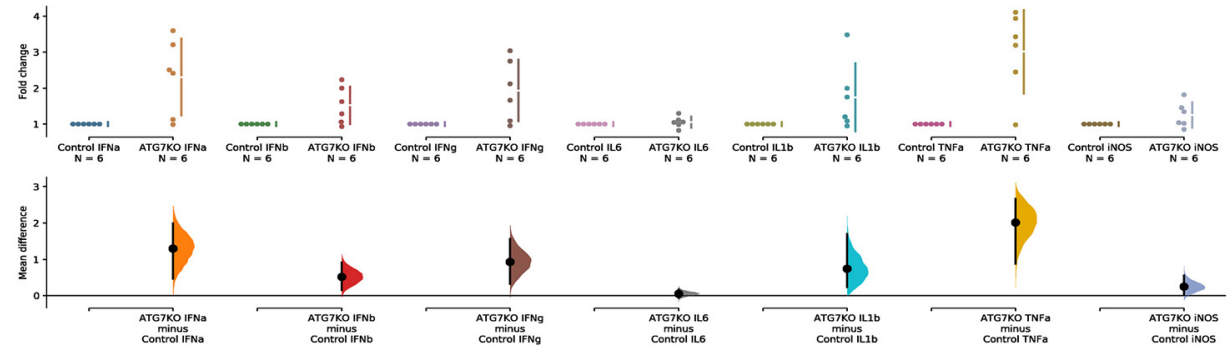

C
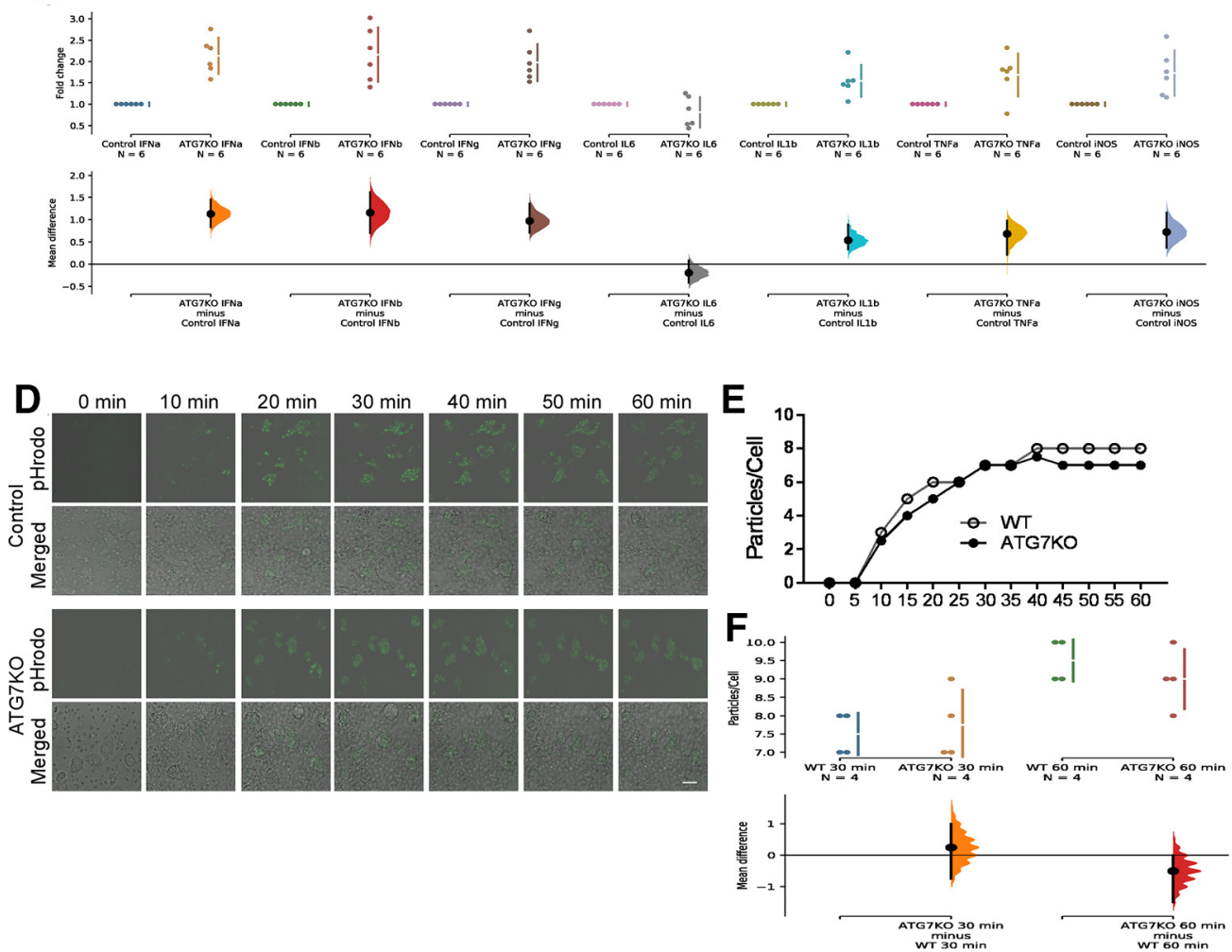

Figure 3. The impact of ATG7 deletion on microglial cytokines and phagocytosis. $\boldsymbol{A}$, Cytokine expression in cortical tissue samples from control and ATG7KO mice $(n=6 ; 3 \mathrm{M}, 3 \mathrm{~F})$. IFNa: UMD: -0.292 [95.0\%Cl $-0.684,0.249] ; p_{\mathrm{t}}: 0.301$. IFNb: UMD: -0.0762 [95.0\% $\mathrm{Cl}-0.329,0.118] ; p_{\mathrm{t}}: 0.527$. IFNg: UMD: is -0.0877 [95.0\% $\left.\mathrm{Cl}-0.486,0.165\right] ; p_{\mathrm{t}}: 0.561$. IL6: UMS: 0.0582 [95.0\%Cl -0.241 , 0.392]; $p_{\mathrm{t}}: 0.753$. IL1b: UMD: 0.0473 [95.0\% $\%$ Cl $\left.-0.568,0.949\right] ; p_{\mathrm{t}}: 0.835$. TNFa: UMD: 0.0262 [95.0\% $\%$ Cl $\left.-0.233,0.28\right] ; p_{\mathrm{t}}: 0.864$. iNOS: UMD: $-0.0356[95.0 \% \mathrm{Cl}-0.35,0.404] ; p_{\mathrm{t}}: 0.834$. $\boldsymbol{B}$, Cytokine expression in hippocampal tissue samples from control and ATG7KO mice $(n=6$; 3M, 3F). IFNa: UMD: 1.31 [95.0\% $\mathrm{Cl} 0.47,1.99] ; p_{\mathrm{t}}: 0.0154$. IFNb: UMD: 0.525 [95.0\%Cl $\left.0.153,0.918\right] ; p_{\mathrm{t}}$ : 0.0486. IFNg: UMD: 0.938 [95.0\%Cl 0.322, 1.56]; $p_{\mathrm{t}}$ : 0.0148. IL6: UMS: 0.0553 [95.0\%Cl $\left.-0.0599,0.174\right] ; p_{\mathrm{t}}$ : 0.51. IL1b: UMD: $0.746[95.0 \% \mathrm{Cl} 0.232,1.7] ; p_{\mathrm{t}}$ : 0.0142. TNFa: UMD: 2.01 [95.0\% Cl 0.878, 2.66]; $p_{\mathrm{t}}: 0.0108$. iNOS: UMD: 0.256 [95.0\%Cl 0.0246, $0.56] ; p_{\mathrm{t}}: 0.118$. $C$, Cytokine expression in purified microglial samples of control and ATG7KO mice $(n=6 ; 3 \mathrm{M}, 3 \mathrm{~F})$. IFNa: UMD: 1.13 [95.0\% Cl 0.828, 1.45]; $p_{\mathrm{t}}:$ 0.0. IFNb: UMD: 1.16 [95.0\% Cl 0.697, 1.62]; $p_{\mathrm{t}}: 0.0$. IFNg: UMD: 0.973 [95.0\%Cl 0.703, 1.36]; $p_{\mathrm{t}}: 0.0$. IL6: UMS: -0.192 [95.0\% $\%$ Cl $-0.419,0.0818] ; p_{t}: 0.164$. IL1b: UMD: 0.541 [95.0\%Cl 0.334, 0.891]; $p_{t}: 0.0$. TNFa: UMD: 0.683 [95.0\%Cl 
continued

0.211, 0.977]; $p_{\mathrm{t}}$ : 0.0138. iNOS: UMD: $0.724[95.0 \% \mathrm{Cl} 0.366,1.16] ; p_{\mathrm{t}}: 0.0002 . \boldsymbol{D}$, Representative time series images $(63 \times)$ showing in vitro uptake of pHrodo zymosan bioparticles (green) in microglia prepared from control and ATG7KO mice; Scale bar - $25 \mu \mathrm{m}$. $\boldsymbol{E}$, Representative time-course showing the number of bioparticles taken up. $\boldsymbol{F}$, Average particles per microglial cell at the 30- and 60min time points $(n=4) ; 30 \mathrm{~min}$ : UMD: $0.25[95.0 \% \mathrm{Cl}-0.75,1.0] ; p_{\mathrm{t}}: 0.365 .60 \mathrm{~min}: \mathrm{UMD}:-0.5[95.0 \% \mathrm{Cl}-1.5,0.0] ; p_{\mathrm{t}}: 0.112$.

Wlodarczyk et al., 2017). However, the exact mechanism by which microglia regulate ODC development and myelination remains to be elucidated. We found that inactivation of autophagy in microglia leads to increased numbers of mature ODCs and markers of myelination. Our results reveal a novel mechanism by which microglia act to maintain homeostasis of ODCs in the CNS. Microglial autophagy deficiency leads to an increased number of mature myelin-producing ODCs and levels of myelin markers in white matter structures, likely reflecting increased myelination. Future study will characterize the myelination structures, such as the thickness of the myelin sheath and the density of internodes along the axons. A recent study reported that the ATG7 gene in microglia plays a role in myelin degradation and clearance (Berglund et al., 2020). It will be interesting to determine whether compromised myelin degradation and clearance of ATG7-deficient microglia contribute to altered levels of myelin and myelination markers and ODC density.

The mechanism underlying the regulation of ODC homeostasis by microglia remains to be determined. It is conceivable that deletion of microglial ATG7 influences the expression of myelin proteins/myelination markers and the density of ODCs through many routes. ATG7 deletion could impose a direct effect on ODCs and their progenitors or act indirectly on other cells such as neurons and astrocytes. It is very hard if not impossible to differentiate these two possibilities at this time. In addition, a recent study revealed that cytokines and growth factors produced by microglia regulate the development of ODCs (Beck et al., 1995; Lloyd and Miron, 2019). We observed a very moderate change in the levels of some cytokines. It is conceivable that suppression of autophagy may alter the basal level of expression of cytokines and growth factors in microglia, which in turn could upregulate the development of ODCs. This will be a focus of future studies.

Apart from altered homeostasis of ODCs, we also observed altered size of the nodes of Ranvier in ATG7KO mice. This may reflect the change in myelination. Indeed, loss of TSC1 in myelinating cells was reported to cause downregulation of quaking and neurofascin, leading to altered nodes of Ranvier along the axons (Pillai et al., 2009; Shi et al., 2018). The nodes of Ranvier play a critical role in propagation of action potential along the axon. It is of great interest to elucidate how impaired microglial autophagy leads to altered size of the nodes of Ranvier.

\section{Myelination in seizure propagation}

Elevated levels of mature ODCs and myelin proteins and increased seizure susceptibility are two overt phenotypic changes in ATG7KO mice. Although it is nearly impossible to prove that the altered myelination is the underlying cause of increased seizure susceptibility, there is a growing evidence to suggest that altered myelination constitutes part of the mechanism underlying epilepsy. Hypomyelination was observed in TSC1 and epileptic conditions (Meikle et al., 2007; Shepherd et al., 2013; Carson et al., 2015; Ercan et al., 2017; Scholl et al., 2017; Schurr et al., 2017; Larson et al., 2018; Sharma et al., 2018; Peters et al., 2019). Loss of function of genes in ODCs was sufficient to cause spontaneous seizures (Lebrun-Julien et al., 2014; Wahl et al., 2014; Figlia et al., 2017; McLane et al., 2017; Shi et al., 2018). Myelination plays a considerable role in determining the rate of stationary transmission of action potentials (ArancibiaCárcamo et al., 2017). Changes in myelination modify brain networks and promote the propagation of seizures (Larson et al., 2018). White matter structures are heavily myelinated and have long been known to be involved in propagation of epileptiform activity between various areas of the cerebral cortices (McCaughran et al., 1976, 1978). We found that autophagy-deficient animals display increased numbers of mature ODCs and higher levels of myelin proteins, and develop severe seizures. Our findings may explain why seizure activities are readily spread to the contralateral side of the brain and why autophagydeficient animals are prone to developing fatal generalized seizures.

Apart from the forebrain commissures, which have been implicated in epileptogenesis and seizure propagation, additional evidence suggests that extracommissural routes, i.e., limbic-brainstem connections, may serve as an alternative path for the spreading and development of severe tonic-clonic seizures and epilepsy-associated mortality (Wada and Sato, 1975). As brainstem seizures have a profound impact on mortality, it is conceivable that myelination in these commissural and extracommissural connections could be changed, leading to facilitated propagation of seizures into the brainstem and resulting in the generalized tonic-clonic seizures and very high mortality seen in autophagy-deficient mice. Future studies will characterize myelination in these structures.

Of particular note, despite the stimulation-evoked large-amplitude electrical activities detected in the ipsilateral cortex in both control and ATG7KO mice, we did not see any epileptiform activities in the ipsilateral cortex. These data suggest that the ipsilateral cortex is inhibited on amygdala stimulation, likely because of ipsilateral cortical spreading of depression (Kelly et al., 1999), and the seizures only readily propagate to the contralateral cortex. Interestingly, mice developed generalized behavioral seizures even in the absence of ipsilateral seizure activity. This suggests that generalized behavioral seizures can be independent of cortical activation, indicating potential 
A

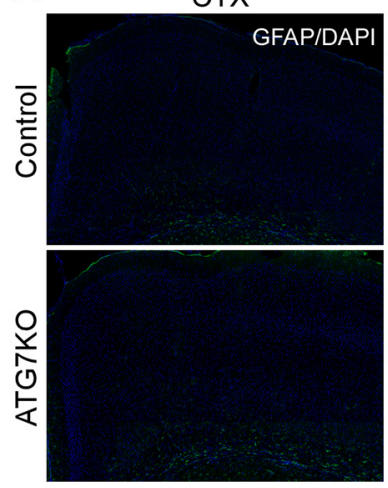

C
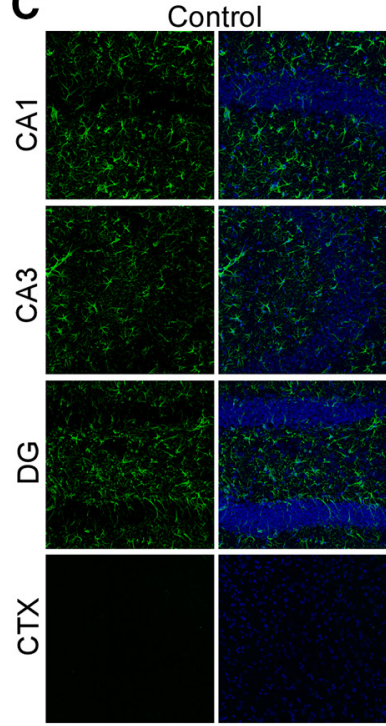

E
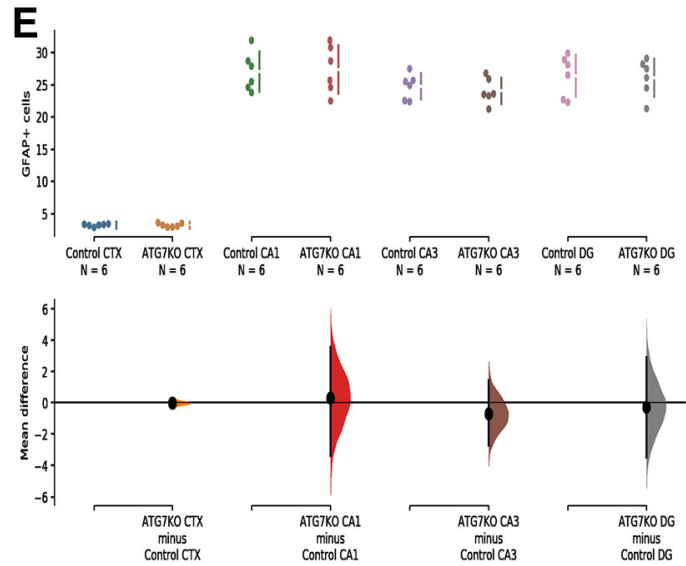

ATG7KO
B
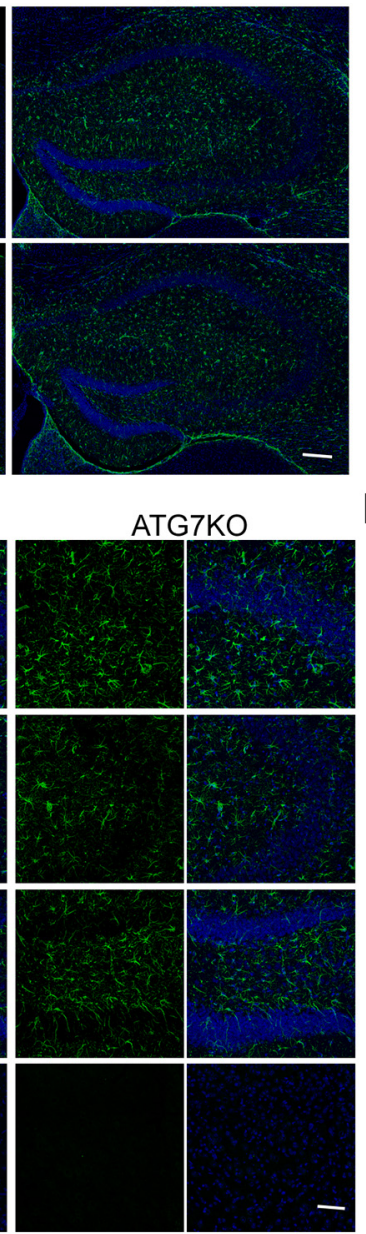

D
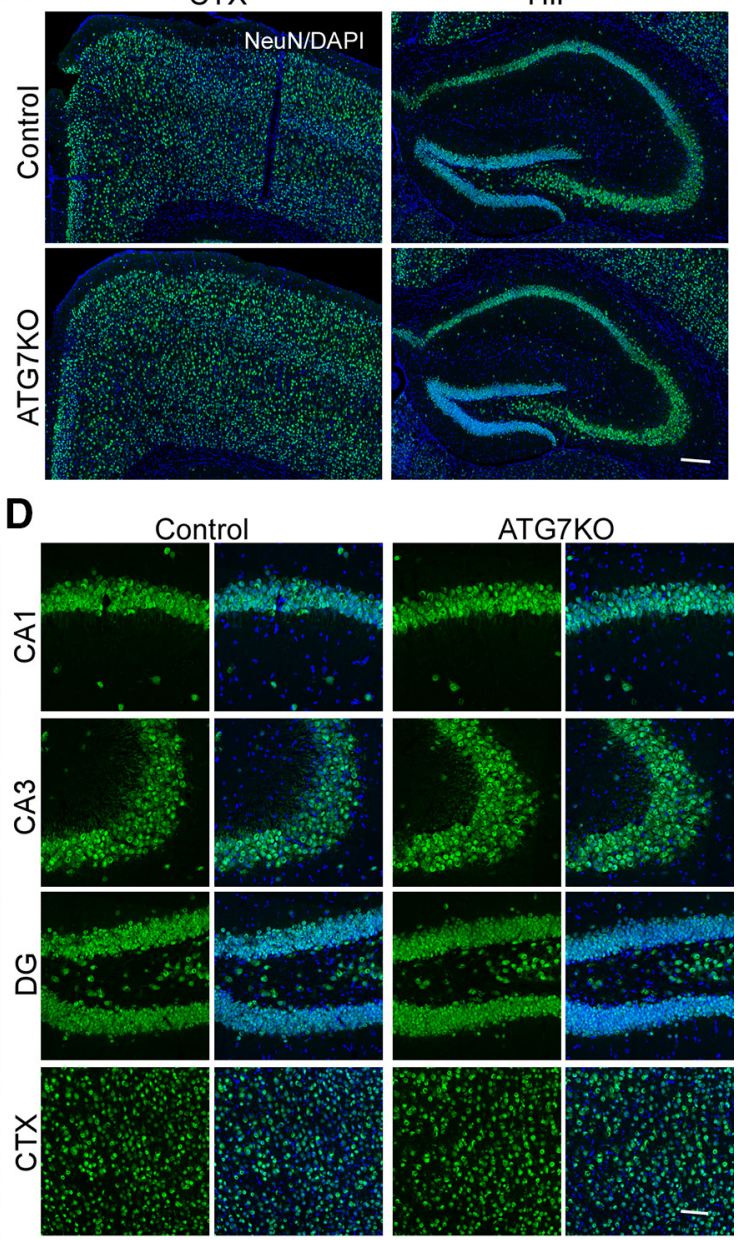

$\mathbf{F}_{z}$
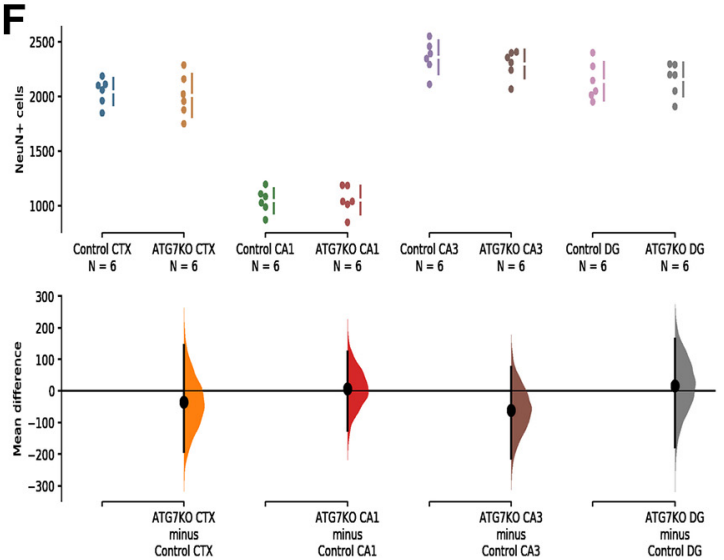

Figure 4. Impact of microglial ATG7 deletion on astrocytes and neurons. A, Full-montage images of GFAP expression in the cortical and hippocampal areas from littermate control and ATG7KO mice. Green: GFAP; Blue: DAPI. Scale bar - $200 \mu \mathrm{m}$. B, Full-scale images of NeuN expression in the cortical and hippocampal areas of littermate control and ATG7KO mice. Green: NeuN; Blue: DAPI. Scale bar $-200 \mu \mathrm{m}$. C. Confocal images $(25 \times)$ of astrocytes from the cortical (CTX) and hippocampal CA1, CA3 and DG regions of littermate control and ATG7KO mice. Green: GFAP; Blue: DAPI. Scale bar - $20 \mu \mathrm{m}$. $\boldsymbol{D}$, Confocal images of neurons from the cortical (CTX) and hippocampal CA1, CA3 and DG regions of littermate control and ATG7KO mice. Scale bar $-20 \mu \mathrm{m}$. $\boldsymbol{E}$, Quantification of GFAP ${ }^{+}$cells per $10^{5} \mu \mathrm{m}^{2} . n=6$ (3 M, 3 F). CTX: UMD: -0.02 [95.0\%Cl $\left.-0.253,0.26\right] ; p_{\mathrm{t}}: 0.881$. CA1: UMD: 0.3 [95.0\% $\mathrm{Cl}-3.35$, 3.57]; $p_{\mathrm{t}}$ : 0.886. CA3: UMD: $-0.7[95.0 \% \mathrm{Cl}-2.7,1.43] ; p_{\mathrm{t}}: 0.549$. DG: UMD: $-0.283[95.0 \% \mathrm{Cl}-3.45,2.9] ; p_{\mathrm{t}}: 0.862 . \boldsymbol{F}$, Quantification of $\mathrm{NeuN}^{+}$cells per $10^{5} \mu \mathrm{m}^{2} . n=6(3 \mathrm{M}, 3 \mathrm{~F})$. CTX: UMD: $-36.0[95.0 \% \mathrm{Cl}-1.91 \mathrm{e}+02,1.44 \mathrm{e}+02] ; p_{\mathrm{t}}: 0.708$. CA1: UMD: $5.83[95.0 \% \mathrm{Cl}-1.25 \mathrm{e}+02,1.24 \mathrm{e}+02] ; p_{\mathrm{t}}: 0.925$. CA3: UMD: $-61.7[95.0 \% \mathrm{Cl}-2.12 \mathrm{e}+02,75.5] ; p_{\mathrm{t}}: 0.466$. DG: UMD: 17.2 $[95.0 \% \mathrm{Cl}-1.77 \mathrm{e}+02,1.64 \mathrm{e}+02] ; p_{\mathrm{t}}: 0.846$. 
A
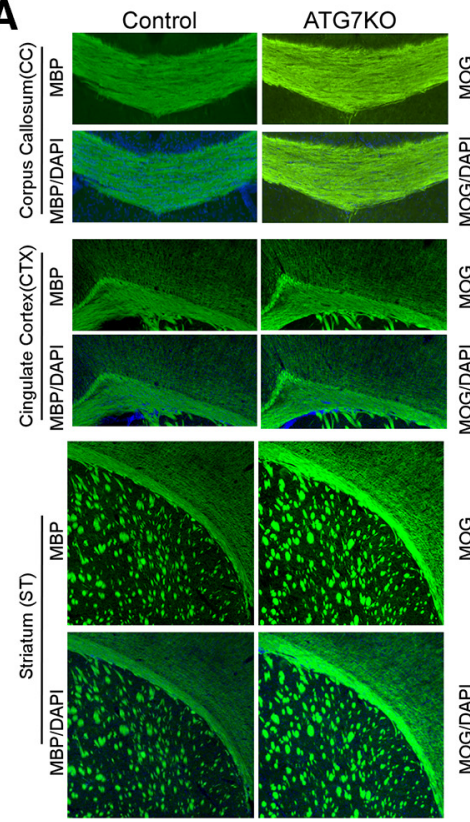

$\mathrm{MBP}$

B<smiles>C=CC=CC=C</smiles>

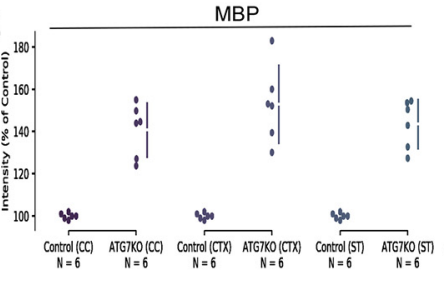

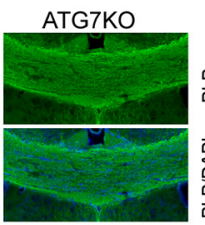
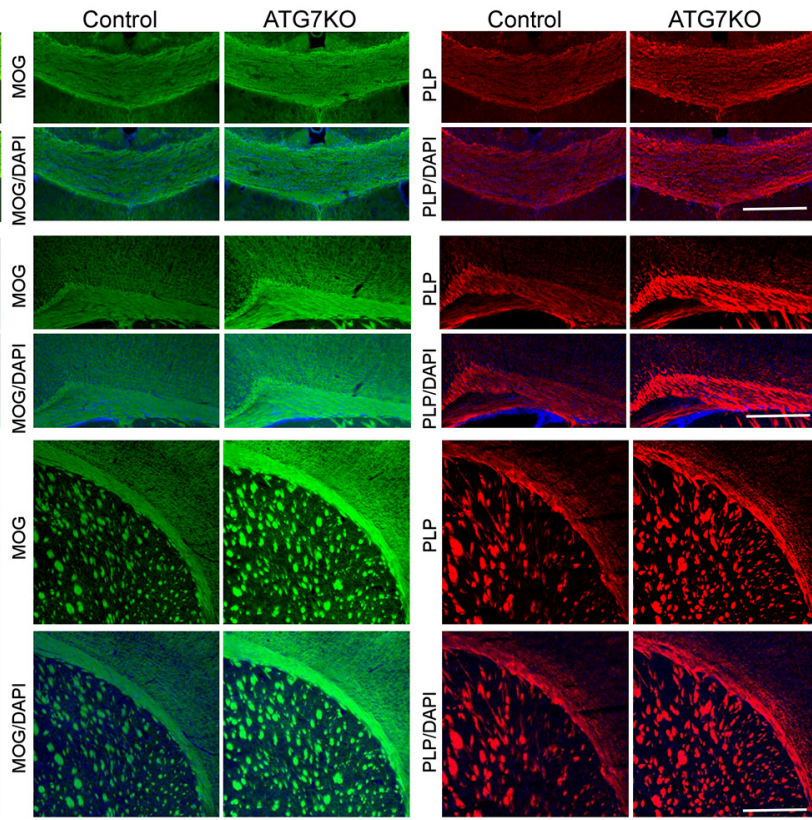

MOG
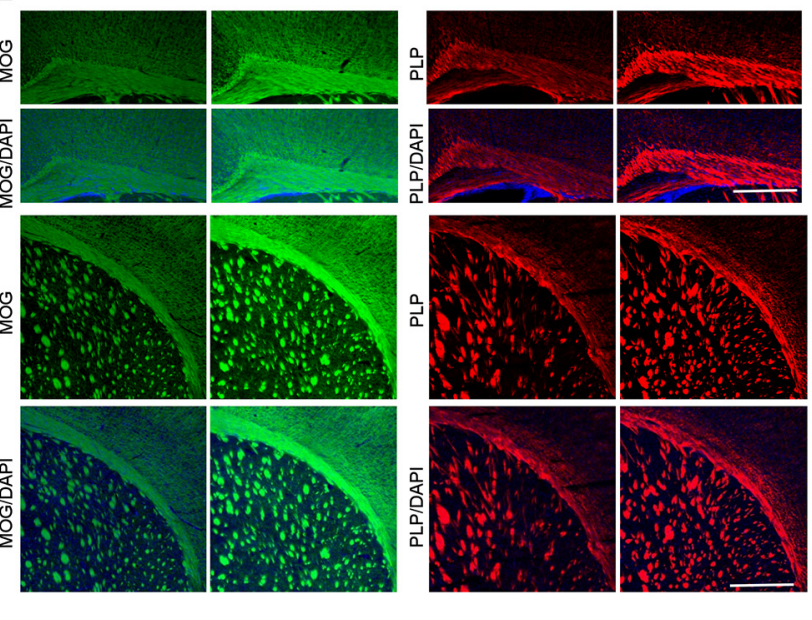

PLP
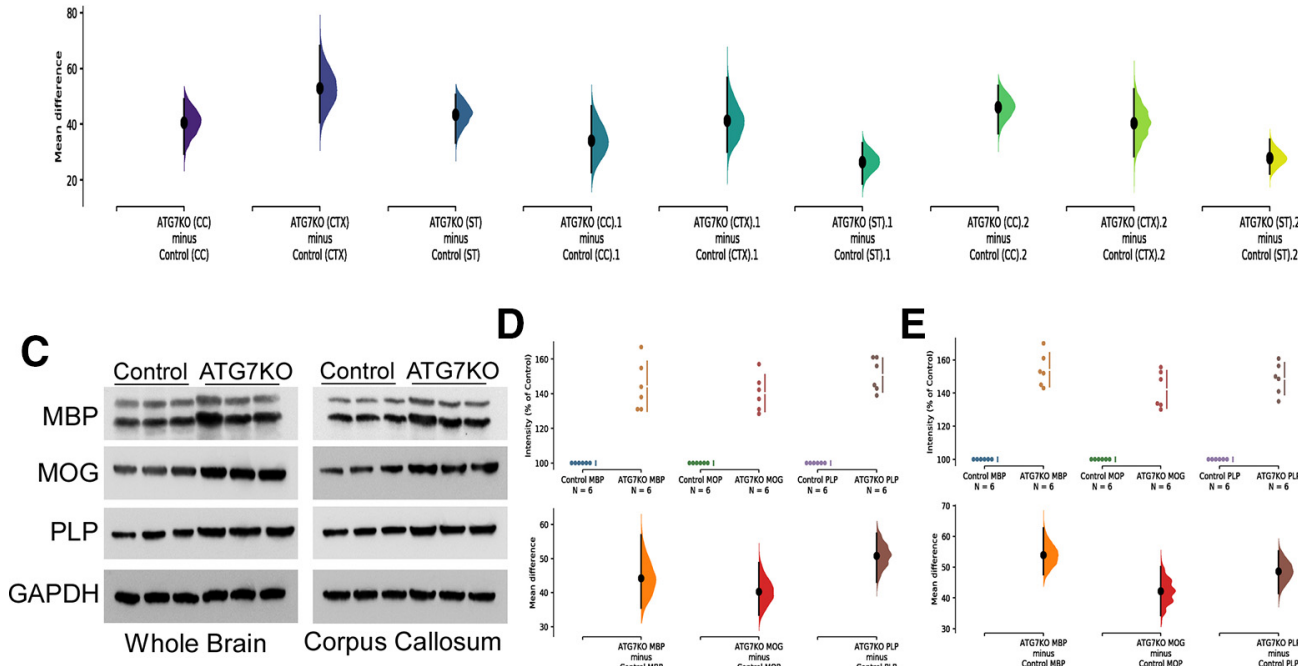

D

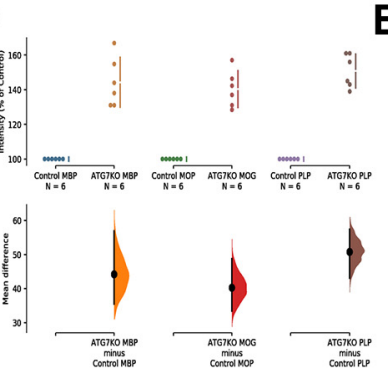

E

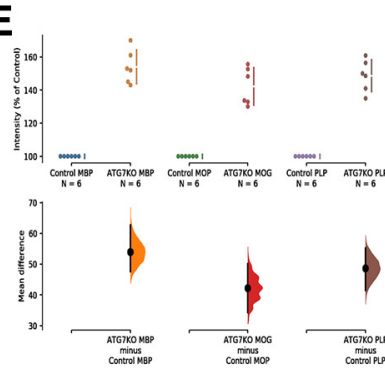

Figure 5. Impact of microglial ATG7 deletion on expression of myelination markers. $\boldsymbol{A}$, Representative images $(20 \times)$ of corpus callosum (CC), cingulate cortex (CX) and striatum (ST) from littermate control and ATG7KO mice stained with MBP, MOG and PLP antibodies. B, Quantification of MBP, MOG and PLP expression in control and ATG7KO mice; $n=6$ ( 3 M, 3 F). MBP: Corpus callosum (CC): UMD: 40.6 [95.0\% Cl 29.5, 48.8]; $p_{\mathrm{t}}$ : 0.0016. Cortex (CTX): UMD: 52.9 [95.0\%Cl 40.7, 68.0]; $p_{\mathrm{t}}: 0.0$. Striatum (ST): UMD: 43.5 [95.0\% $\%$ 33.5, 50.5]; $p_{\mathrm{t}}$ : 0.0. MOG: Corpus callosum (CC): UMD: 34.2 [95.0\%Cl 23.0, 46.4]; $p_{\mathrm{t}}$ : 0.0002. Cortex (CTX): UMD: 41.3 [95.0\% Cl 30.3, 56.5]; $p_{\mathrm{t}}$ : 0.0. Striatum (ST): UMD: 26.6 [95.0\% $\left.\mathrm{Cl} 18.8,33.2\right] ; p_{\mathrm{t}}: 0.0$. PLP: Corpus callosum (CC): UMD: 46.2 [95.0\% $\mathrm{Cl} 36.9,53.6] ; p_{\mathrm{t}}:$ 0.0. Cortex (CTX): UMD: 40.5 [95.0\% Cl 28.6, 52.4]; $p_{\mathrm{t}}$ : 0.0006. Striatum (ST): UMD: 27.9 [95.0\% 0 Cl 22.5, 34.3]; $p_{\mathrm{t}}$ : 0.0004. C, Western blot analysis of MBP, MOG and PLP protein levels from whole brain and corpus callosum lysates; $n=6$ (3 M, 3 F). D, Quantification of MBP, MOG and PLP protein levels from whole brain. MBP: UMD: 44.3 [95.0\% Cl 35.5, 56.9]; $p_{t}: 0.0004$. MOG: UMD: 40.3 [95.0\% $\mathrm{Cl} 33.4,48.8]$; $p_{\mathrm{t}}$ : 0.0002. PLP: UMD: 50.8 [95.0\%Cl 43.2, 57.3]; $p_{\mathrm{t}}$ : 0.0006. E, Quantification of MBP, MOG and PLP protein levels from isolated corpus callosum lysates. MBP: UMD: 54.0 [95.0\%Cl 47.7, 62.7]; $p_{\mathrm{t}}$ : 0.0. MOG: UMD: $42.2[95.0 \% \mathrm{Cl} 34.3,50.1] ; p_{\mathrm{t}}:$ 0.0. PLP: UMD: $48.6[95.0 \% \mathrm{Cl} 41.5,55.2] ; p_{\mathrm{t}}: 0.0$. 
A

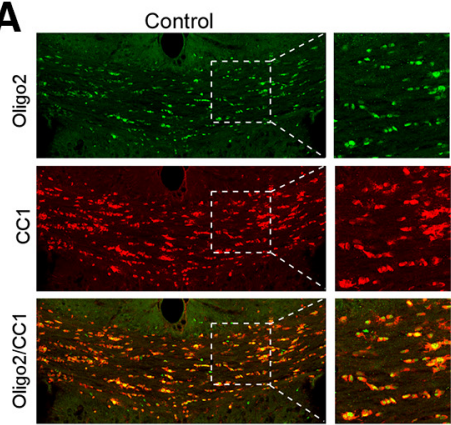

B
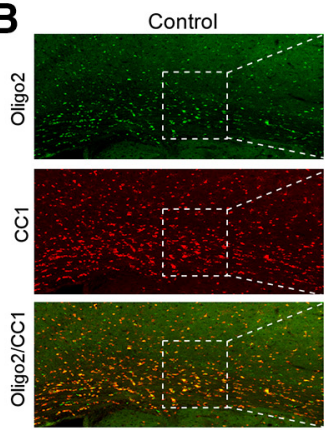

D
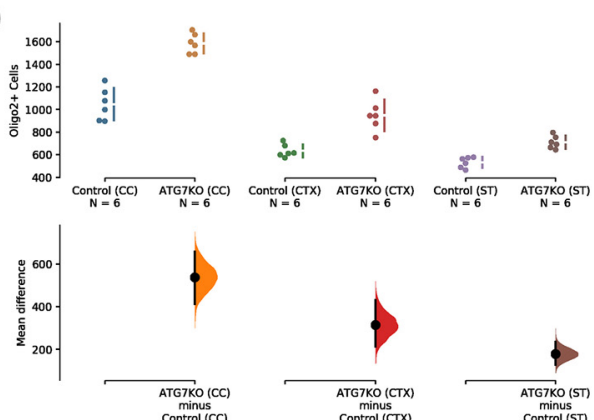

$\mathbf{F}$
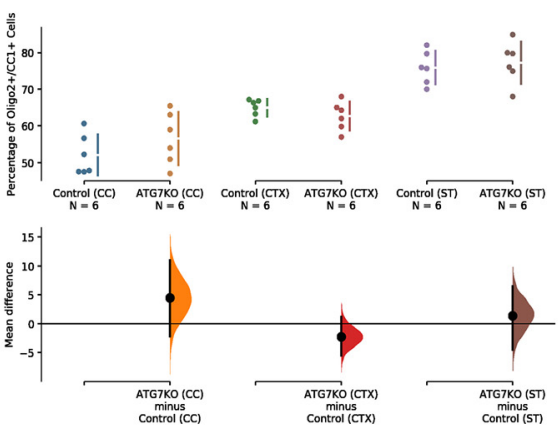

ATG7KO
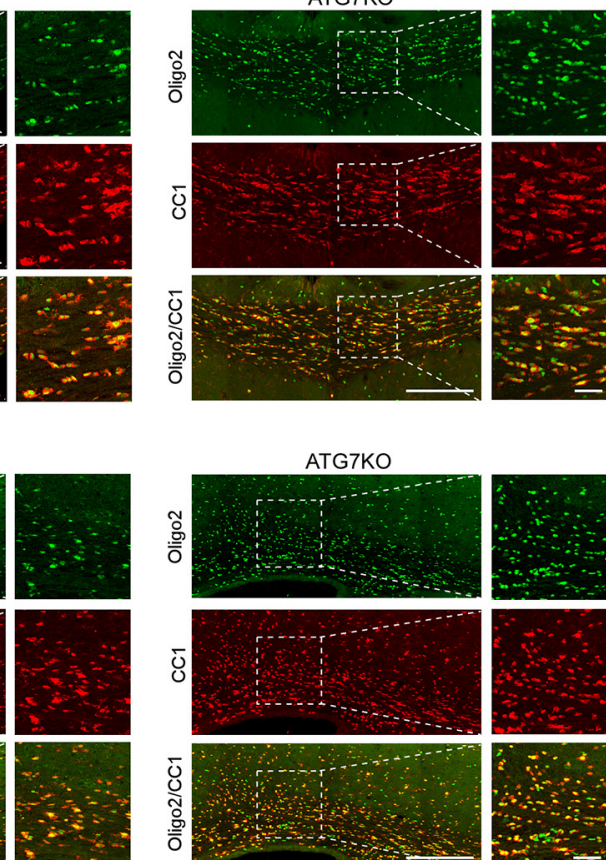

ATG7KO
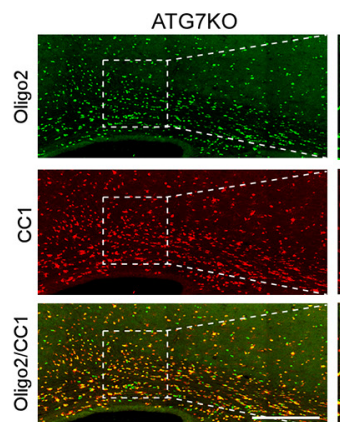
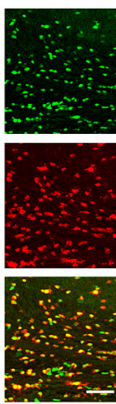

C
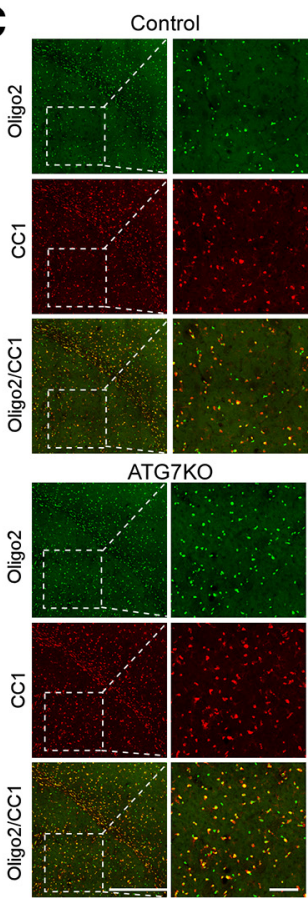

E
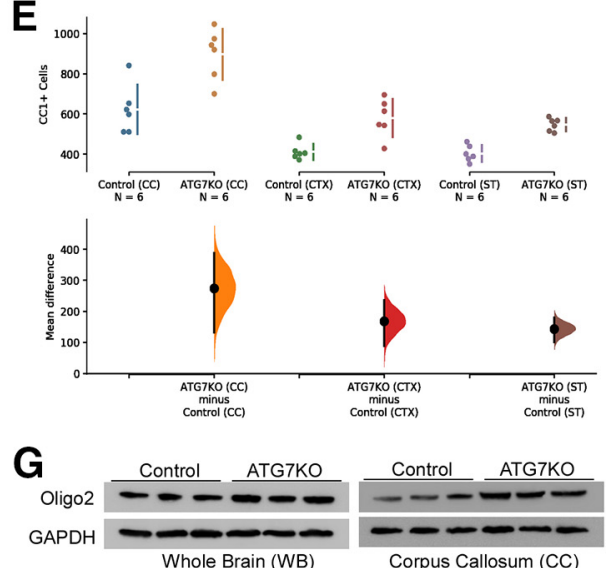

$\mathrm{H}$

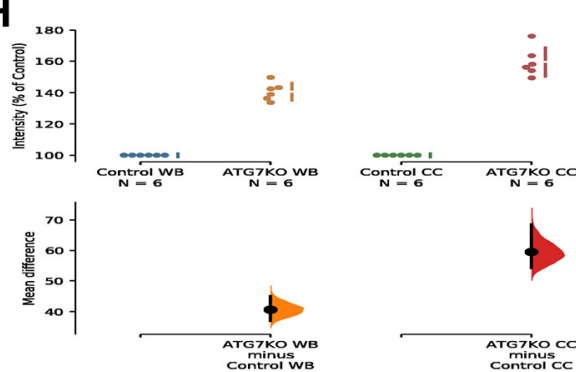

Figure 6. Impact of microglial ATG7 deletion on oligodendrocytes. $\boldsymbol{A}-\boldsymbol{C}$, Representative confocal images $(25 \times)$ of corpus callosum (CC) $(\boldsymbol{A})$, cingulate cortex (CTX) $(\boldsymbol{B})$ and striatum (ST) (C) from littermate control and ATG7KO mice stained with an oligodendrocyte marker (Olig2; green) and a marker of mature oligodendrocytes (CC-1; red). Scale bar $-20 \mu \mathrm{m}, 5 \mu \mathrm{m}$. D-F, Quantification of Olig2 ${ }^{+}$ cells, $\mathrm{CC} 1^{+}$cells and Olig2 ${ }^{+} / \mathrm{CC} 1^{+}$cells per $0.5 \mathrm{~mm} 2 ; n=6(3 \mathrm{M}, 3 \mathrm{~F})$. Oligo2 ${ }^{+}$cells $(\boldsymbol{D})$ : Corpus callosum (CC): UMD: $5.38 \mathrm{e}+02$ [95.0\% Cl 4.13e+02, 6.58e+02]; $p_{\mathrm{t}}$ : 0.0. Cortex (CTX): UMD: 3.14e+02 [95.0\% Cl 2.14e+02, 4.3e+02]; $p_{\mathrm{t}}$ : 0.0. Striatum (ST): UMD: $1.78 \mathrm{e}+02[95.0 \% \mathrm{Cl} 1.27 \mathrm{e}+02,2.36 \mathrm{e}+02] ; p_{\mathrm{t}}: 0.0$. CC1 ${ }^{+}$cells $(\boldsymbol{E}):$ Corpus callosum (CC): UMD: $2.74 \mathrm{e}+02[95.0 \% \mathrm{Cl} 1.32 \mathrm{e}+02$, 3.87e+02]; $p_{\mathrm{t}}:$ 0.0046. Cortex (CTX): UMD: $1.68 \mathrm{e}+02$ [95.0\% Cl 88.7, 2.36e+02]; $p_{\mathrm{t}}: 0.0024$. Striatum (ST): UMD: $1.43 \mathrm{e}+02$ [95.0\% $\mathrm{Cl} 1.01 \mathrm{e}+02,1.79 \mathrm{e}+02] ; p_{\mathrm{t}}: 0.0$. Olig2 ${ }^{+} / \mathrm{CC} 1^{+}$cells $(\boldsymbol{F})$ : Corpus callosum (CC): UMD: 4.49 [95.0\% $\left.\mathrm{Cl}-2.21,10.9\right] ; p_{\mathrm{t}}: 0.245$. Cortex (CTX): UMD: -2.26 [95.0\%Cl -5.52, 1.15]; $p_{\mathrm{t}}$ : 0.254. Striatum (ST): UMD: 1.39 [95.0\%Cl -4.52, 6.48]; $p_{\mathrm{t}}$ : 0.636. G, Western blot analysis of Olig2 protein levels in whole brain and isolated corpus callosum lysates. $\boldsymbol{H}$, Quantification of Olig2 protein levels in whole brain and isolated corpus callosum lysates $n=6$ (3 m and $3 \mathrm{f}$ ). Whole brain: Oligo2: UMD: 40.7 [95.0\% $\mathrm{Cl}$ 36.9, 45.1]; $p_{\mathrm{t}}$ : 0.0. Corpus callosum (CC): Oligo2: UMD: 59.5 [95.0\% $\mathrm{Cl} 54.1,68.5] ; p_{\mathrm{t}}: 0.0$. 
A

Corpus Callosum (CC)
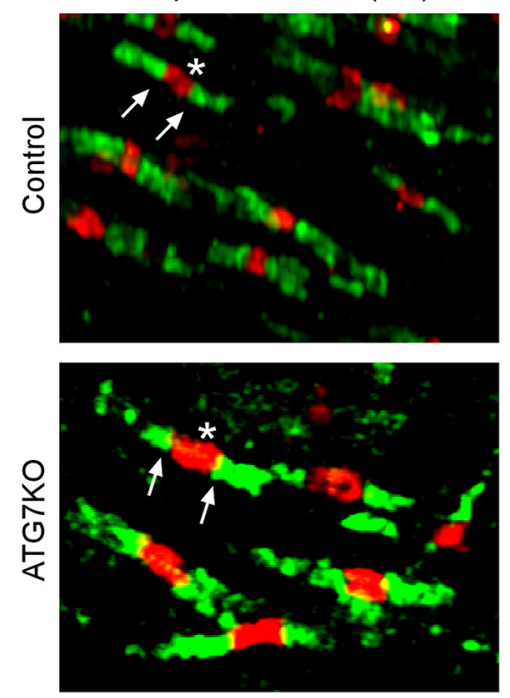

Cingulate Cortex (CTX)
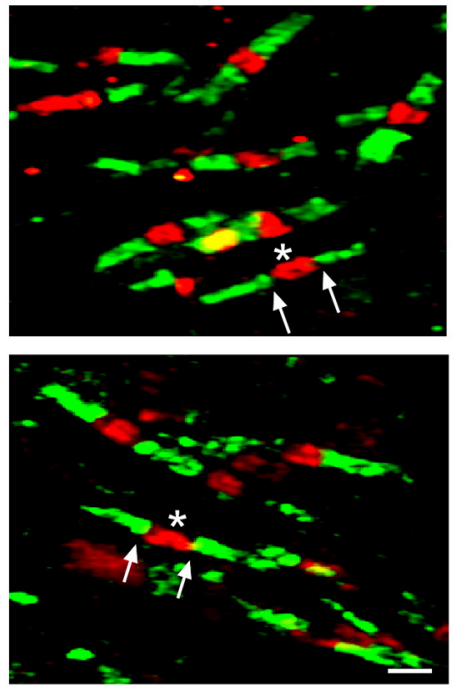
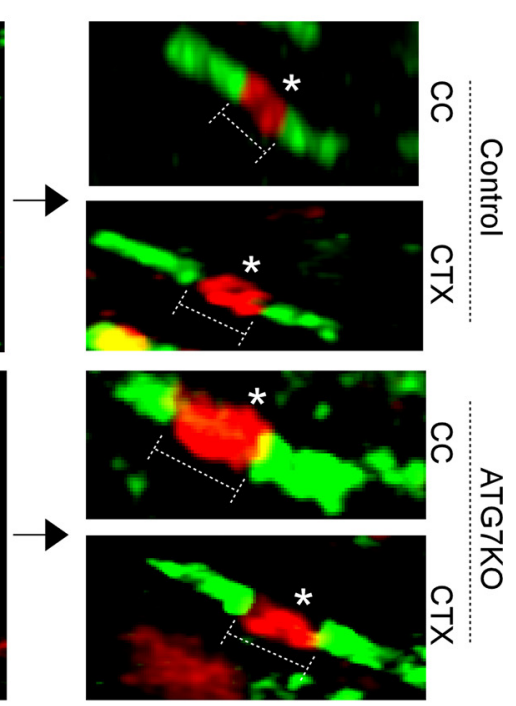

B

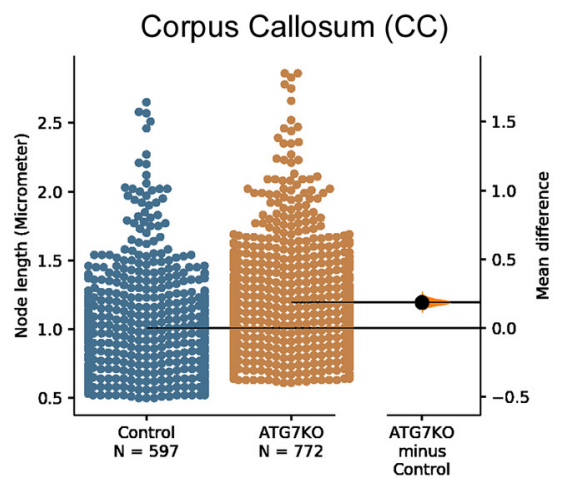

D

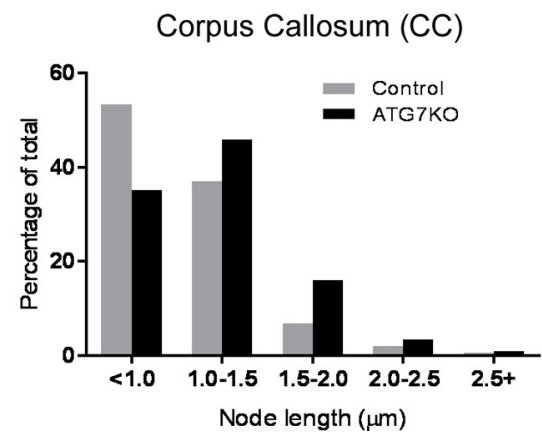

C

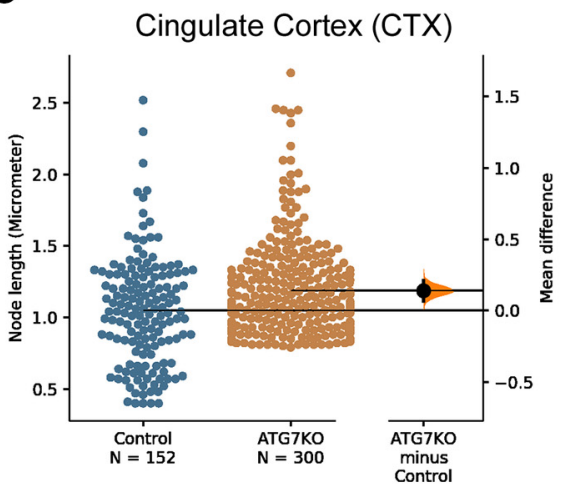

E

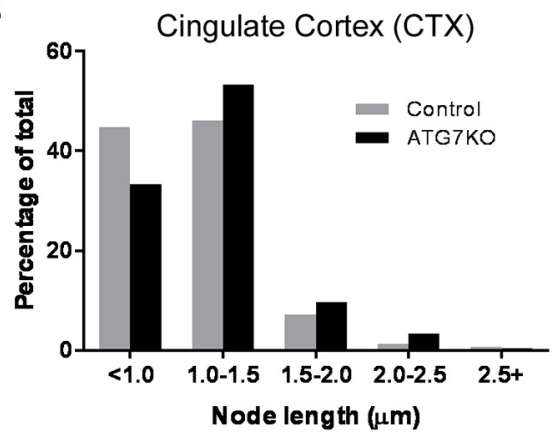

Figure 7. Microglial deletion of ATG7 changes the size of the nodes of Ranvier. $\boldsymbol{A}$, Representative confocal images $(63 \times)$ of IHC staining for sodium channel Nav1.6 (red) and CASPR (green) in the corpus callosum (CC) and cortex (CTX) areas of littermate control and ATG7KO mice. Scale bar - $20 \mu \mathrm{m}$. B, $\boldsymbol{C}$, Quantification of the average size of nodes in the CC $(\boldsymbol{B})$ and CTX $(\boldsymbol{C})$ in littermate control and ATG7KO mice. Data points were acquired from 6 pairs of animals (3 M, $3 \mathrm{~F})$. Corpus callosum (CC): UMD: 0.188 [95.0\% $\mathrm{Cl}$ $0.148,0.231] ; p_{\mathrm{t}}: 0.0$. Cingulate cortex (CTX): UMD: 0.141 [95.0\% Cl 0.0685, 0.211]; $p_{\mathrm{t}}: 0.0$. D, E, Distribution of the length of nodes in the corpus callosum $(\boldsymbol{D})$ and cingulate cortex $(\boldsymbol{E})$ of littermate control and ATG7KO mice.

involvement of subcortical and brainstem structures in generalized seizures.

A growing body of evidence demonstrates that microglia influence neuronal excitability and seizure susceptibility
(Badimon et al., 2020; Umpierre et al., 2020; Wu et al., 2020). We found that excessive activation of mTOR in TSC1-deficient mice leads to severe spontaneous seizures, involving a noninflammatory mechanism (Zhao et al., 2018). Our recent 
study revealed that deletion of microglial mTOR increases excitatory neuronal death and spontaneous recurrent seizures (Zhao et al., 2020). Here, we found that deletion of Atg7 in microglia promotes increased amounts of mature ODCs and myelination markers. Interestingly, hypomyelination was reported in both human TSC1 patients and TSC1-deficient animal models (Meikle et al., 2007; Shepherd et al., 2013; Carson et al., 2015; Ercan et al., 2017; Scholl et al., 2017; Schurr et al., 2017; Larson et al., 2018; Sharma et al., 2018; Peters et al., 2019). Because mTOR signaling and autophagy are connected, the contrasting outcomes are intriguing and perhaps reflect the different cell types in which the mTOR or autophagy signaling is altered. For example, in a previous study in a mouse model, TSC1 was deleted in neurons (Meikle et al., 2007). Also, in human TSC1 patients, TSC1 is presumably mutated in neurons (and all other cells), resulting in large balloonlike cells. In contrast, in the present study, ATG7 was restrictively deleted in microglia. It is conceivable that mTOR and autophagy signaling in neurons has opposite effects on ODC homeostasis compared with signaling in microglia.

Apart from impacting myelination and ODCs, we acknowledge that microglial autophagy deficiency could also impact CNS homeostasis through other means, leading to increased seizure susceptibility and high mortality. For example, inactivation of microglial autophagy was reported to impair synaptic pruning and learning behavior (Kim et al., 2017). Thus, autophagy deficiency may alter synaptic pruning of microglia, which could in turn impact neuronal circuitry development and maturation, resulting in increased seizure susceptibility. Moreover, although we did not see a significant change in the density of astrocytes, astrocytes still could be impacted by autophagy deficiency in microglia and the homeostatic activity of astrocytes could be compromised, resulting in severe seizures. Finally, we observed a moderate increase of cytokines in ATG7KO mice. Cytokines have been implicated in seizures (Vezzani et al., 2011). It is conceivable that elevated cytokines may contribute to the increased seizure severity in ATG7KO mice.

The Cx3cr1-cre line mediates the deletion of ATG7KO in microglia during early stages of brain development, which likely has a broad impact on the CNS. Therefore, an ideal approach would be to employ an inducible Cx3cr1-creERT line to delete ATG7KO in the mature brain. However, our recent study revealed that the Cx3cr1-CreER inducible line has spontaneous leakage (Zhao et al., 2019). We found that up to $25 \%$ of microglia express GFP reporter before tamoxifen treatment. This prohibits us from pursuing this approach. In the present study, the impact of microglial deletion of ATG7 on myelination and ODCs was characterized in the mature brain. Previous studies reported that microglia regulate ODC proliferation and myelination of neuronal axons in early brain development (Miron, 2017; Wlodarczyk et al., 2017; Lloyd and Miron, 2019). Future studies will examine whether microglial ATG7KO deletion has any impact on myelination and the density of ODCs in the developing brain.
$\mathrm{Cx} 3 \mathrm{Cr} 1$ is also expressed in some peripheral monocytes, i.e., macrophages, including those of the perivasculature, choroid plexus and meninges. We recently reported an important role of autophagy in Cx3cr1+ mononuclear cells in intestinal fibrosis (Mathur et al., 2019). Thus, ATG7 is likely deleted in macrophages in ATG7KO (ATG7 ${ }^{\mathrm{C} \times 3 \mathrm{Cr} 1-\mathrm{CreCKO}}$ ) mice. Although under nonperturbed conditions there is very little, if any, infiltration of macrophages into the brain, we cannot rule out the possibility that ATG7 deletion in macrophages impacts seizure susceptibility to convulsants.

In summary, microglial autophagy plays a critical role in maintaining CNS homeostasis. Impairment of microglial autophagy in ATG7KO mice results in severe generalized seizures leading to death. Histologically, the phenotype includes a significant increase of ODC density and myelin proteins in white matter regions of the brain. Our findings have significant implications in understanding the basis of, and developing treatments for, severe generalized and refractory seizures as well as epilepsy-associated mortality.

\section{References}

Abiega O, Beccari S, Diaz-Aparicio I, Nadjar A, Layé S, Leyrolle Q, Gómez-Nicola D, Domercq M, Pérez-Samartín A, Sánchez-Zafra V, Paris I, Valero J, Savage JC, Hui CW, Tremblay MË, Deudero JJP, Brewster AL, Anderson AE, Zaldumbide L, Galbarriatu L, et al. (2016) Neuronal hyperactivity disturbs ATP microgradients, impairs microglial motility, and reduces phagocytic receptor expression triggering apoptosis/microglial phagocytosis uncoupling. PLoS Biol 14:e1002466.

Abraham J, Fox PD, Condello C, Bartolini A, Koh S (2012) Minocycline attenuates microglia activation and blocks the longterm epileptogenic effects of early-life seizures. Neurobiol Dis 46:425-430.

Arancibia-Cárcamo IL, Ford MC, Cossell L, Ishida K, Tohyama K, Attwell D (2017) Node of Ranvier length as a potential regulator of myelinated axon conduction speed. Elife 6:e23329.

Badimon A, Strasburger HJ, Ayata P, Chen X, Nair A, Ikegami A, Hwang P, Chan AT, Graves SM, Uweru JO, Ledderose C, Kutlu MG, Wheeler MA, Kahan A, Ishikawa M, Wang YC, Loh YHE, Jiang JX, Surmeier DJ, Robson SC, et al. (2020) Negative feedback control of neuronal activity by microglia. Nature 586:417-423.

Beck KD, Powell-Braxton L, Widmer HR, Valverde J, Hefti F (1995) Igf1 gene disruption results in reduced brain size, CNS hypomyelination, and loss of hippocampal granule and striatal parvalbumincontaining neurons. Neuron 14:717-730.

Beirowski B, Wong KM, Babetto E, Milbrandt J (2017) mTORC1 promotes proliferation of immature Schwann cells and myelin growth of differentiated Schwann cells. Proc Natl Acad Sci USA 114: E4261-E4270.

Berglund R, Guerreiro-Cacais AO, Adzemovic MZ, Zeitelhofer M, Lund $\mathrm{H}$, Ewing $\mathrm{E}$, Ruhrmann S, Nutma E, Parsa R, ThessenHedreul M, Amor S, Harris RA, Olsson T, Jagodic M (2020). Microglial autophagy-associated phagocytosis is essential for recovery from neuroinflammation. Sci Immunol 5:eabb5077.

Brewster AL, Lugo JN, Patil VV, Lee WL, Qian Y, Vanegas F, Anderson AE (2013) Rapamycin reverses status epilepticus-induced memory deficits and dendritic damage. PLoS One 8: e57808.

Carson RP, Van Nielen DL, Winzenburger PA, Ess KC (2012) Neuronal and glia abnormalities in Tsc1-deficient forebrain and partial rescue by rapamycin. Neurobiol Dis 45:369-380.

Carson RP, Kelm ND, West KL, Does MD, Fu C, Weaver G, McBrier E, Parker B, Grier MD, Ess KC (2015) Hypomyelination following 
deletion of Tsc2 in oligodendrocyte precursors. Ann Clin Transl Neurol 2:1041-1054.

Choi I, Zhang Y, Seegobin SP, Pruvost M, Wang Q, Purtell K, Zhang B, Yue Z (2020) Microglia clear neuron-released alpha-synuclein via selective autophagy and prevent neurodegeneration. Nat Commun 11:1386.

Cunha LD, Yang M, Carter R, Guy C, Harris L, Crawford JC, Quarato G, Boada-Romero E, Kalkavan H, Johnson MDL, Natarajan S, Turnis ME, Finkelstein D, Opferman JT, Gawad C, Green DR (2018) LC3-associated phagocytosis in myeloid cells promotes tumor immune tolerance. Cell 175:429-441.e16.

Di Nardo A, Wertz MH, Kwiatkowski E, Tsai PT, Leech JD, GreeneColozzi E, Goto J, Dilsiz P, Talos DM, Clish CB, Kwiatkowski DJ, Sahin M (2014) Neuronal Tsc1/2 complex controls autophagy through AMPK-dependent regulation of ULK1. Hum Mol Genet 23:3865-3874.

Ebrahimi-Fakhari D, Saffari A, Wahlster L, Di Nardo A, Turner D, Lewis TL Jr, Conrad C, Rothberg JM, Lipton JO, Kölker S, Hoffmann GF, Han MJ, Polleux F, Sahin M (2016) Impaired mitochondrial dynamics and mitophagy in neuronal models of tuberous sclerosis complex. Cell Rep 17:1053-1070.

Ercan E, Han JM, Di Nardo A, Winden K, Han MJ, Hoyo L, Saffari A, Leask A, Geschwind DH, Sahin M (2017) Neuronal CTGF/CCN2 negatively regulates myelination in a mouse model of tuberous sclerosis complex. J Exp Med 214:681-697.

Eyo UB, Peng J, Swiatkowski P, Mukherjee A, Bispo A, Wu LJ (2014) Neuronal hyperactivity recruits microglial processes via neuronal NMDA receptors and microglial $\mathrm{P} 2 \mathrm{Y} 12$ receptors after status epilepticus. J Neurosci 34:10528-10540.

Figlia G, Norrmén C, Pereira JA, Gerber D, Suter U (2017) Dual function of the PI3K-Akt-mTORC1 axis in myelination of the peripheral nervous system. Elife 6:e29241.

Ford MC, Alexandrova O, Cossell L, Stange-Marten A, Sinclair J, Kopp-Scheinpflug C, Pecka M, Attwell D, Grothe B (2015) Tuning of Ranvier node and internode properties in myelinated axons to adjust action potential timing. Nat Commun 6:8073.

Friedman LG, Lachenmayer ML, Wang J, He L, Poulose SM, Komatsu M, Holstein GR, Yue Z (2012) Disrupted autophagy leads to dopaminergic axon and dendrite degeneration and promotes presynaptic accumulation of $\alpha$-synuclein and LRRK2 in the brain. J Neurosci 32:7585-7593.

Goddard GV, Mclntyre DC, Leech CK (1969) A permanent change in brain function resulting from daily electrical stimulation. Exp Neurol 25:295-330.

He Y, She H, Zhang T, Xu H, Cheng L, Yepes M, Zhao Y, Mao Z (2018) p38 MAPK inhibits autophagy and promotes microglial inflammatory responses by phosphorylating ULK1. J Cell Biol 217:315-328.

Heckmann BL, Teubner BJW, Tummers B, Boada-Romero E, Harris L, Yang M, Guy CS, Zakharenko SS, Green DR (2019) LC3-associated endocytosis facilitates beta-amyloid clearance and mitigates neurodegeneration in murine Alzheimer's disease. Cell 178:536551.e14.

Hopperton KE, Mohammad D, Trépanier MO, Giuliano V, Bazinet RP (2018) Markers of microglia in post-mortem brain samples from patients with Alzheimer's disease: a systematic review. Mol Psychiatry 23:177-198.

Jiang M, Liu L, He X, Wang H, Lin W, Wang H, Yoon SO, Wood TL, Lu QR (2016) Regulation of PERK-elF2alpha signalling by tuberous sclerosis complex-1 controls homoeostasis and survival of myelinating oligodendrocytes. Nat Commun 7:12185.

Kelly ME, Battye RA, Mclntyre DC (1999) Cortical spreading depression reversibly disrupts convulsive motor seizure expression in amygdala-kindled rats. Neuroscience 91:305-313.

Kim HJ, Cho MH, Shim WH, Kim JK, Jeon EY, Kim DH, Yoon SY (2017) Deficient autophagy in microglia impairs synaptic pruning and causes social behavioral defects. Mol Psychiatry 22:15761584.

Larson VA, Mironova Y, Vanderpool KG, Waisman A, Rash JE, Agarwal A, Bergles DE (2018) Oligodendrocytes control potassium accumulation in white matter and seizure susceptibility. Elife 7: e34829.

Lebrun-Julien F, Bachmann L, Norrmén C, Trötzmüller M, Köfeler H, Rüegg MA, Hall MN, Suter U (2014) Balanced mTORC1 activity in oligodendrocytes is required for accurate CNS myelination. J Neurosci 34:8432-8448.

Lee JW, Nam H, Kim LE, Jeon Y, Min H, Ha S, Lee Y, Kim SY, Lee SJ, Kim EK, Yu SW (2019) TLR4 (toll-like receptor 4) activation suppresses autophagy through inhibition of $\mathrm{FOXO} 3$ and impairs phagocytic capacity of microglia. Autophagy 15:753-770.

Levine B, Klionsky DJ (2004) Development by self-digestion: molecular mechanisms and biological functions of autophagy. Dev Cell 6:463-477.

Liu J, Reeves C, Michalak Z, Coppola A, Diehl B, Sisodiya SM, Thom $M$ (2014) Evidence for mTOR pathway activation in a spectrum of epilepsy-associated pathologies. Acta Neuropathol Commun 2:71.

Lloyd AF, Miron VE (2019) The pro-remyelination properties of microglia in the central nervous system. Nat Rev Neurol 15:447-458.

Mathur R, Alam MM, Zhao X-F, Liao Y, Shen J, Morgan S, Huang T, Lee H, Lee E, Huang Y, Zhu X (2019) Induction of autophagy in Cx3cr1(+) mononuclear cells limits IL-23/IL-22 axis-mediated intestinal fibrosis. Mucosal Immunol 12:612-623.

McCaughran JA Jr, Corcoran ME, Wada JA (1976) Development of kindled amygdaloid seizures after section of the forebrain commissures in rats. Folia Psychiatr Neurol Jpn 30:65-71.

McCaughran JA Jr, Corcoran ME, Wada JA (1978) Role of the forebrain commissures in amygdaloid kindling in rats. Epilepsia 19:1933.

McLane LE, Bourne JN, Evangelou AV, Khandker L, Macklin WB, Wood TL (2017) Loss of tuberous sclerosis complex1 in adult oligodendrocyte progenitor cells enhances axon remyelination and increases myelin thickness after a focal demyelination. J Neurosci 37:7534-7546.

McMahon J, Huang X, Yang J, Komatsu M, Yue Z, Qian J, Zhu X, Huang $Y$ (2012) Impaired autophagy in neurons after disinhibition of mammalian target of rapamycin and its contribution to epileptogenesis. J Neurosci 32:15704-15714.

Meikle L, Talos DM, Onda H, Pollizzi K, Rotenberg A, Sahin M, Jensen FE, Kwiatkowski DJ (2007) A mouse model of tuberous sclerosis: neuronal loss of Tsc1 causes dysplastic and ectopic neurons, reduced myelination, seizure activity, and limited survival. J Neurosci 27:5546-5558.

Miron VE (2017) Microglia-driven regulation of oligodendrocyte lineage cells, myelination, and remyelination. J Leukoc Biol 101:11031108.

Miron VE, Boyd A, Zhao J-W, Yuen TJ, Ruckh JM, Shadrach JL, van Wijngaarden $\mathrm{P}$, Wagers AJ, Williams A, Franklin RJM, FfrenchConstant C (2013) M2 microglia and macrophages drive oligodendrocyte differentiation during CNS remyelination. Nat Neurosci 16:1211-1218.

Mo M, Eyo UB, Xie M, Peng J, Bosco DB, Umpierre AD, Zhu X, Tian DS, Xu P, Wu LJ (2019) Microglial P2Y12 receptor regulates seizure-induced neurogenesis and immature neuronal projections. $J$ Neurosci 39:9453-9464.

Morales JC, Alvarez-Ferradas C, Roncagliolo M, Fuenzalida M, Wellmann M, Nualart FJ, Bonansco C (2014) A new rapid kindling variant for induction of cortical epileptogenesis in freely moving rats. Front Cell Neurosci 8:200.

Nguyen LH, Brewster AL, Clark ME, Regnier-Golanov A, Sunnen CN, Patil VV, D'Arcangelo G, Anderson AE (2015) mTOR inhibition suppresses established epilepsy in a mouse model of cortical dysplasia. Epilepsia 56:636-646.

Nimmerjahn A, Kirchhoff F, Helmchen F (2005) Resting microglial cells are highly dynamic surveillants of brain parenchyma in vivo. Science 308:1314-1318.

Nonoda $Y$, Saito $Y$, Itoh $M$, Nakagawa $E$, Sugai $K$, Takahashi A, Otsuki T, Saito Y, Arima K, Mizuguchi M, Goto Y-i, Sasaki M (2009) Activation of microglia/macrophages expressing phosphorylated 
S6 ribosomal protein in a case of hemimegalencephaly with progressive calcification and atrophy. J Neurol Sci 287:52-59.

Paolicelli RC, Bolasco G, Pagani F, Maggi L, Scianni M, Panzanelli P, Giustetto M, Ferreira TA, Guiducci E, Dumas L, Ragozzino D, Gross CT (2011) Synaptic pruning by microglia is necessary for normal brain development. Science 333:1456-1458.

Peters JM, Struyven RR, Prohl AK, Vasung L, Stajduhar A, Taquet M, Bushman JJ, Lidov H, Singh JM, Scherrer B, Madsen JR, Prabhu SP, Sahin M, Afacan O, Warfield SK (2019) White matter mean diffusivity correlates with myelination in tuberous sclerosis complex. Ann Clin Transl Neurol 6:1178-1190.

Pillai AM, Thaxton C, Pribisko AL, Cheng JG, Dupree JL, Bhat MA (2009) Spatiotemporal ablation of myelinating glia-specific neurofascin (Nfasc NF155) in mice reveals gradual loss of paranodal axoglial junctions and concomitant disorganization of axonal domains. J Neurosci Res 87:1773-1793.

Rubinsztein DC, DiFiglia M, Heintz N, Nixon RA, Qin ZH, Ravikumar B, Stefanis L, Tolkovsky A (2005) Autophagy and its possible roles in nervous system diseases, damage and repair. Autophagy 1:1122.

Samie M, Lim J, Verschueren E, Baughman JM, Peng I, Wong A, Kwon Y, Senbabaoglu Y, Hackney JA, Keir M, Mckenzie B, Kirkpatrick DS, van Lookeren Campagne M, Murthy A (2018) Selective autophagy of the adaptor TRIF regulates innate inflammatory signaling. Nat Immunol 19:246-254.

Sanjuan MA, Dillon CP, Tait SWG, Moshiach S, Dorsey F, Connell S, Komatsu M, Tanaka K, Cleveland JL, Withoff S, Green DR (2007) Toll-like receptor signalling in macrophages links the autophagy pathway to phagocytosis. Nature 450:1253-1257.

Sato M, Racine RJ, McIntyre DC (1990) Kindling: basic mechanisms and clinical validity. Electroencephalogr Clin Neurophysiol 76:459472.

Schafer DP, Lehrman EK, Kautzman AG, Koyama R, Mardinly AR, Yamasaki R, Ransohoff RM, Greenberg ME, Barres BA, Stevens B (2012) Microglia sculpt postnatal neural circuits in an activity and complement-dependent manner. Neuron 74:691-705.

Schartz ND, Wyatt-Johnson SK, Price LR, Colin SA, Brewster AL (2018) Status epilepticus triggers long-lasting activation of complement $\mathrm{C} 1 \mathrm{q}-\mathrm{C} 3$ signaling in the hippocampus that correlates with seizure frequency in experimental epilepsy. Neurobiol Dis 109:163-173.

Scholl T, Mühlebner A, Ricken G, Gruber V, Fabing A, Samueli S, Gröppel G, Dorfer C, Czech T, Hainfellner JA, Prabowo AS, Reinten RJ, Hoogendijk L, Anink JJ, Aronica E, Feucht M (2017) Impaired oligodendroglial turnover is associated with myelin pathology in focal cortical dysplasia and tuberous sclerosis complex. Brain Pathol 27:770-780.

Schurr J, Coras R, Rössler K, Pieper T, Kudernatsch M, Holthausen H, Winkler P, Woermann F, Bien CG, Polster T, Schulz R, Kalbhenn T, Urbach H, Becker A, Grunwald T, Huppertz HJ, GilNagel A, Toledano R, Feucht M, Mühlebner A, et al. (2017) Mild malformation of cortical development with oligodendroglial hyperplasia in frontal lobe epilepsy: a new clinico-pathological entity. Brain Pathol 27:26-35.

Sharma P, Powell KL, Wlodek ME, O'Brien TJ, Gilby KL (2018) Delayed myelination and neurodevelopment in male seizure-prone versus seizure-resistant rats. Epilepsia 59:753-764.

Shepherd C, Liu J, Goc J, Martinian L, Jacques TS, Sisodiya SM, Thom M (2013) A quantitative study of white matter hypomyelination and oligodendroglial maturation in focal cortical dysplasia type II. Epilepsia 54:898-908.

Shi Q, Saifetiarova J, Taylor AM, Bhat MA (2018) mTORC1 activation by loss of Tsc1 in myelinating glia causes downregulation of quaking and neurofascin 155 leading to paranodal domain disorganization. Front Cell Neurosci 12:201.

Sierra A, Encinas JM, Deudero JJ, Chancey JH, Enikolopov G, Overstreet-Wadiche LS, Tsirka SE, Maletic-Savatic M (2010) Microglia shape adult hippocampal neurogenesis through apoptosis-coupled phagocytosis. Cell Stem Cell 7:483-495.

Sosunov AA, Wu X, McGovern RA, Coughlin DG, Mikell CB, Goodman RR, McKhann GM 2nd (2012) The mTOR pathway is activated in glial cells in mesial temporal sclerosis. Epilepsia 53 [Suppl 1]:78-86.

Umpierre AD, Bystrom LL, Ying Y, Liu YU, Worrell G, Wu LJ (2020) Microglial calcium signaling is attuned to neuronal activity in awake mice. Elife 9:e56502.

van Vliet EA, Otte WM, Wadman WJ, Aronica E, Kooij G, de Vries HE, Dijkhuizen RM, Gorter JA (2016) Blood-brain barrier leakage after status epilepticus in rapamycin-treated rats I: magnetic resonance imaging. Epilepsia 57:59-69.

Vezzani A, French J, Bartfai T, Baram TZ (2011) The role of inflammation in epilepsy. Nat Rev Neurol 7:31-40.

Wada JA, Sato M (1975) The generalized convulsive seizure state induced by daily electrical stimulation of the amygdala in split brain cats. Epilepsia 16:417-430.

Wahl SE, McLane LE, Bercury KK, Macklin WB, Wood TL (2014) Mammalian target of rapamycin promotes oligodendrocyte differentiation, initiation and extent of CNS myelination. J Neurosci 34:4453-4465.

Wlodarczyk A, Holtman IR, Krueger M, Yogev N, Bruttger J, Khorooshi R, Benmamar-Badel A, de Boer-Bergsma JJ, Martin NA, Karram K, Kramer I, Boddeke EW, Waisman A, Eggen BJ, Owens T (2017) A novel microglial subset plays a key role in myelinogenesis in developing brain. EMBO J 36:3292-3308.

Wu W, Li Y, Wei Y, Bosco DB, Xie M, Zhao MG, Richardson JR, Wu LJ (2020) Microglial depletion aggravates the severity of acute and chronic seizures in mice. Brain Behav Immun 89:245-255.

Wyatt-Johnson SK, Brewster AL (2020) Emerging roles for microglial phagocytic signaling in epilepsy. Epilepsy Curr 20:33-38.

Wyatt-Johnson SK, Herr SA, Brewster AL (2017) Status epilepticus triggers time-dependent alterations in microglia abundance and morphological phenotypes in the hippocampus. Front Neurol 8:700.

Yamamoto A, Yue Z (2014) Autophagy and its normal and pathogenic states in the brain. Annu Rev Neurosci 37:55-78.

Zhao X, Liao Y, Morgan S, Mathur R, Feustel P, Mazurkiewicz J, Qian J, Chang J, Mathern GW, Adamo MA, Ritaccio AL, Gruenthal M, Zhu X, Huang Y (2018) Noninflammatory changes of microglia are sufficient to cause epilepsy. Cell Rep 22:2080-2093.

Zhao XF, Alam MM, Liao Y, Huang T, Mathur R, Zhu X, Huang Y (2019) Targeting microglia using Cx3cr1-Cre lines: revisiting the specificity. eNeuro 6:ENEURO.0114-19.2019.

Zhao XF, Liao Y, Alam MM, Mathur R, Feustel P, Mazurkiewicz JE, Adamo MA, Zhu XC, Huang Y (2020) Microglial mTOR is neuronal protective and antiepileptogenic in the pilocarpine model of temporal lobe epilepsy. J Neurosci 40:7593-7608. 